DIW BERLIN

Discussion

Papers
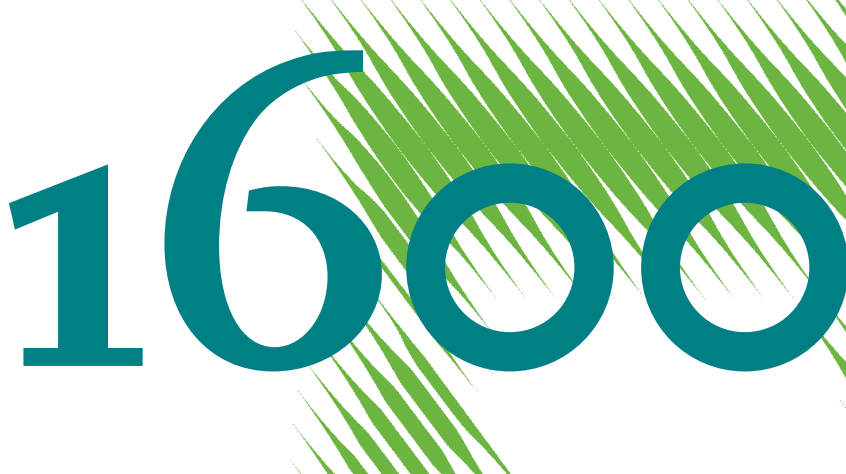

1

(

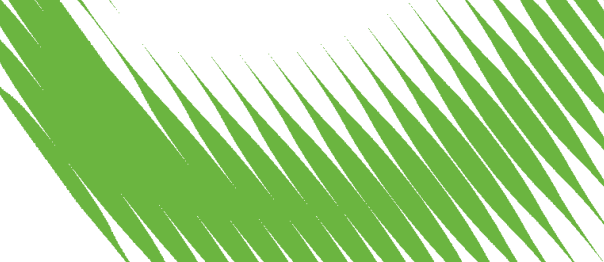

1111
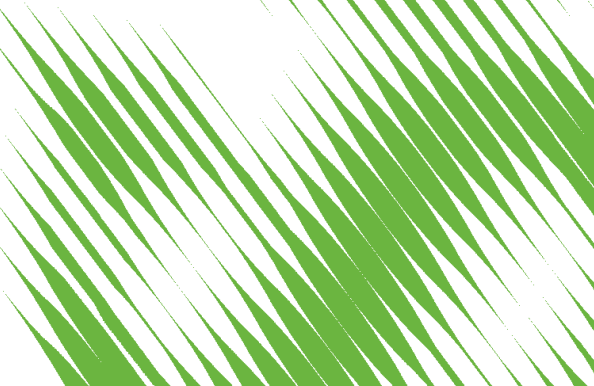

11

11111

Peer Effects in Parental Leave Decisions 
Opinions expressed in this paper are those of the author(s) and do not necessarily reflect views of the institute.

IMPRESSUM

(C) DIW Berlin, 2016

DIW Berlin

German Institute for Economic Research

Mohrenstr. 58

10117 Berlin

Tel. +49 (30) $89789-0$

Fax +49 (30) $89789-200$

http://www.diw.de

ISSN electronic edition 1619-4535

Papers can be downloaded free of charge from the DIW Berlin website:

http://www.diw.de/discussionpapers

Discussion Papers of DIW Berlin are indexed in RePEc and SSRN:

http://ideas.repec.org/s/diw/diwwpp.html

http://www.ssrn.com/link/DIW-Berlin-German-Inst-Econ-Res.html 


\title{
Peer Effects in Parental Leave Decisions
}

\author{
Clara Welteke* and Katharina Wrohlich ${ }^{\dagger}$
}

July 22, 2016

\begin{abstract}
This paper analyzes to what extent parental leave decisions of mothers with young children depend on the decisions made by their coworkers. The identification of peer effects, which are defined as indirect effects of the behavior of a social reference group on individual outcomes, bears various challenges due to correlated characteristics within social groups and endogenous group membership. We overcome these challenges by exploiting quasi-random variation in the costs of parental leave during a narrow window around a cutoff date, induced by a parental leave benefit reform in Germany. The reform encourages mothers to remain at home during the first year following childbirth. Administrative linked employeremployee panel data enable us to assign a peer group to all individuals who work in the same establishment and occupational group. While there is a growing literature on peer effects, few studies look at peer effects in the context of parental leave decisions. We argue, however, that mothers with young children are particularly susceptible to peer behavior at the workplace due to preferences for conformity with peer group behavior as well as the career-related uncertainty that mothers face. Our results suggest that maternal decisions regarding the length of parental leave are significantly influenced by coworker decisions, in particular in situations with high uncertainty.
\end{abstract}

Keywords: peer effects, social interaction, labor supply, family policy

JEL: C31, J22, D04

*DIW Berlin and IZA Research Affiliate, cwelteke@diw.de

${ }^{\dagger}$ DIW Berlin, kwrohlich@diw.de 


\section{Introduction}

Parental leave policies and maternal reactions to it are a widely discussed topic among policymakers and researchers. Policies that enable prolonged parental leave spells, including parental leave benefits and job protection policies, may help protect young families and encourage fertility. However, mothers who take long leaves after giving birth might loosen their labor market attachment with the well-known consequences of decreased career prospects and life-time earnings. ${ }^{1}$ Furthermore, employment interruptions due to motherhood can result in greater gender inequality. $^{2}$

Parental leave behavior, and more generally labor supply of mothers with young children, differs greatly across time and regions. ${ }^{3}$ Numerous studies explain part of these changes over time or the variation between countries based on standard economic models, attributing them to differences in financial incentives caused by institutional diversity. However, institutional differences cannot explain all divergence in the labor supply behavior of mothers across countries. ${ }^{4}$ More recently, a growing strand of the literature on female labor supply and parental leave decisions suggests alternative or complementary explanations for differences between countries or over time. For example, Fernandez (2013) attributes part of the increase in women's labor supply in the US over the last century to changes in culture. While there is a tradition in sociology and anthropology of focusing on the importance of social structure, norms, and culture, economists have long neglected social influences on individual behavior. However, an increasing number of economic studies are based on the assumption that individuals do not exist in isolation but are embedded within networks of relationships, such as families, coworkers, neighbors, friends, or socio-economic groups. For example, several studies analyze the influence of social interaction on labor supply within geographic neighborhoods (e.g. Weinberg, Reagan, and Yankow, 2004; Fogli and Veldkamp, 2011) and family networks (e.g Del Boca, Locatelli, and Pasqua, 2000; Dahl, Løken, and Mogstad, 2014; Neumark and Postlewaite, 1998; Nicoletti, Salvanes, and Tominey, 2016).

In this study, we focus on the parental leave decisions of mothers and how these are affected

\footnotetext{
${ }^{1}$ For the non-linear relationship between maternal leave duration and labor market outcomes, see Ruhm (1998).

${ }^{2}$ Increasing maternal labor supply over the life-cycle is a key factor in closing the gender wage gap (e.g. Polachek and Xiang, 2006).

${ }^{3}$ Classical references for the evolution of women's employment in the US include, among others, Goldin (1990) and Blau and Kahn (2006). For Germany, time trends in female employment patterns are documented e.g. by Fitzenberger and Wunderlich (2004). Cross-country differences explored e.g. by Bick and Fuchs-Schündeln (2014) and Blundell et al. (2013)

${ }^{4}$ For example, the paper by Bick and Fuchs-Schündeln (2014) shows that differences in male labor supply behavior between US and Western Europe can be largely explained by economic variables such as the tax system and the distribution of wages. However, the same model can only explain about 40 percent of the difference in female labor supply based on these economic variables. Similarly, a paper by Dearing et al. (2007) comparing two culturally very similar countries - Austria and West Germany - shows that differences in financial incentives only explain 20 percent of the total difference in the full time employment rate of mothers with children under age 10 in both countries. Moreover, several papers show that, although mothers in East and West Germany have shared the same institutional setting for more than 20 years, there are still persistent differences in labor supply behavior (see Rosenfeld et al., 2004; Grunow and Müller, 2012).
} 
by peers at the workplace. While many different social networks are important for individual decisions, we believe that workplace social networks play a particularly important role, because the workplace facilitates the formation of social ties and, thereby, the transmission of behavioral norms and career-related information.

In the following, we refer to peer effects as the effects of a social reference group's behavior on individual outcomes. There are several channels through which the change in parental leave behavior of a social reference group can influence individual decisions. These include preferences for conformity to social norms, learning about the costs and benefits of parental leave, as well as leisure complementarities.

We argue that preferences for conformity and the transmission of information about the costs and benefits of a (long) parental leave are both likely mechanism of peer effects in our context. Information transmission is expected to be particularly important in situations with high career-related uncertainty. Observing peer mothers at the workplace, more specifically the employers' reaction to peer mothers' parental leave choices, reduces uncertainty concerning the consequences of leave choices. Preferences for conformity to peer behavior are expected to be particularly important in situations with changing social norms. Our results are consistent with a social learning model where information provided by peers reduces social and careerrelated uncertainty. Other channels that can give rise to peer effects include the transmission of practical knowledge about the existence and organizational details of the parental leave program, as well as leisure complementarities or work externalities. Leisure complementarities would imply that mothers benefit from taking leave simultaneously, whereas work externalities occur if the absence of one mother makes it more difficult for her coworkers to take leave. While the the transmission of practical knowledge can be ruled out as a mechanism that drives our results because the parental leave benefit program is universal and well-known, leisure complementarities and work externalities are unlikely to be relevant because of the temporal distance of the parental leave of peer mothers and their coworkers.

We believe that our study has significant policy relevant implications. When social interaction effects are quantitatively important, policy interventions on single agents might have large effects through so-called social multipliers (see Glaeser, Scheinkman, and Sacerdote, 2003). Although empirical studies frequently attempt to infer individual behavior from observed aggregate outcomes, when there is social interaction, aggregate coefficients will be larger than individual coefficients because there is a direct effect of policy changes on individual behavior and an indirect effect through the effects on the social reference group.

The identification of peer effects is challenging due to correlated characteristics within social groups and endogenous group membership (see Manski, 1993; Blume, Brock, Durlauf, and Ioannides, 2010, for an overview). Several studies (e.g. Dahl et al., 2014; Brown, 2013) suggest using policy reforms as instruments to address the identification challenges. We follow this suggestion and identify social interaction effects in the labor supply of mothers with young children using the exogenous variation introduced by the 2007 reform of the parental leave benefit (Elterngeld) in Germany, which, in particular, encourages high-income mothers to remain at home during 
the first 12 months following childbirth. ${ }^{5}$ We use administrative linked employer-employee data from the Institute for Employment Research (IAB), which enables us to assign a peer group to all individuals who work in the same establishment and occupational group. The identifying variation stems from the exposure of our sample to peer mothers who gave birth within a narrow window either before or after the parental leave benefit reform. While other papers used German administrative labor market data to identify peer effects in the context of fertility (see Pink et al., 2013), productivity (see Cornelissen, Dustmann, and Schönberg, 2013), and job searches (see Dustmann, Glitz, and Schönberg, 2011), this is the first paper to focus on peer effects in the context of parental leave behavior in Germany.

Our results suggest that maternal decisions regarding the length of their own parental leave are significantly influenced by their coworkers' decisions. We find that a mother is about 30 percentage points more likely to stay at home for the first year if her peer(s) decide(s) to do so in response to the parental leave benefit reform. This effect corresponds to the Local Average Treatment Effect (LATE). We also estimate the Intention to Treat Effect (ITT), showing that having peers who gave birth after the introduction of the new parental leave benefit increases the probability that a mother takes a leave of at least one year by 7 percentage points in contrast to mothers who have peers who gave birth shortly before this date. The results of analyses for those subgroups for whom uncertainty regarding the employer's reaction to parental leave decisions is higher, suggest that information transmission and the reduction of uncertainty that comes with observing peer behavior are among the critical channels driving peer effects in our context. Our results hold following a large number of robustness checks as well as alternative specifications of the estimation sample and the definition of peers.

The paper is organized as follows. In the next section we describe some stylized facts on maternal employment in Germany and discuss the institutional details of the 2007 parental leave reform that we use as an instrument in the empirical analysis. Section 3 sketches our methodological approach and explains our identification strategy. In section 4, we describe our data set and present some selected descriptive statistics. The baseline results of our empirical analysis and several robustness checks are presented in Section 5. This is followed by a discussion of the possible peer effect mechanisms based on heterogenous effects for different subgroups in Section 6. Section 7 concludes.

\section{Institutional Setting and Stylized Facts}

Maternal employment is of increasing policy relevance in Germany, because low fertility rates and an increasing old-age dependency ratio underlie a growing imbalance in public finances. Traditionally, employment rates of mothers are relatively low in West Germany, compared to other European countries such as France, the UK or the Nordic countries. However, since 2006, the employment rate of mothers with children above the age of one has been increasing,

\footnotetext{
${ }^{5}$ See Bergemann and Riphahn (2015), Geyer et al. (2015), Kluve and Schmitz (2014), and Kluve and Tamm (2013) for an analysis of the effects of the 2007 parental leave benefit reform on maternal employment.
} 
as seen in Figure 1. For example, the employment rate of mothers with a child aged 2 to 3 years was 42 percent in 2006, increasing to 54 percent in 2012. At the same time, the employment rate of mothers with children aged 1 to 2 years or 3 to 6 years has also been increasing. Over this same period, the employment rates of mothers with children below the age of one decreased. Consistent with this evidence, the mean duration of employment interruption following childbirth decreased between 2004 and 2010 (see Wrohlich et al., 2012).

Figure 1: Maternal employment rates by age of youngest child

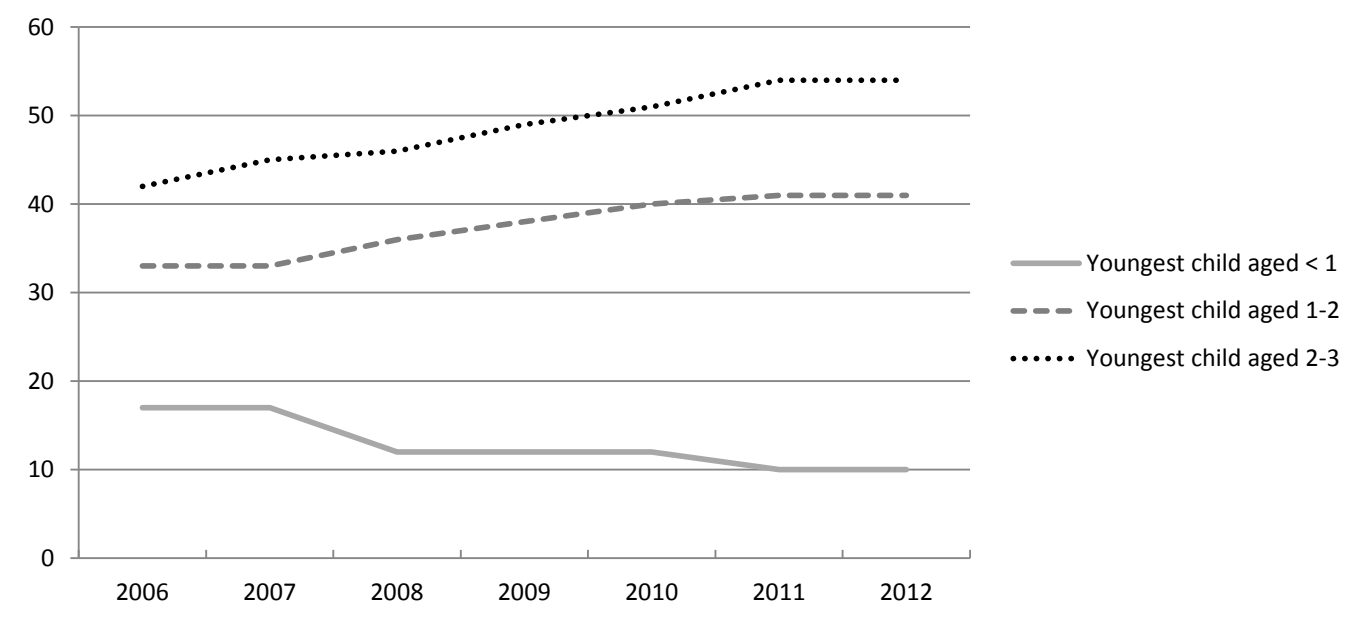

Source: Federal Ministry of Family Affairs, Senior Citizens, Women and Youth 2012.

Since 2005, several policy reforms have affected maternal employment. A major family policy reform was the expansion of subsidized child care for children under three years. Since 2005 several child care reforms have been carried out that have successively increased the availability of subsidized child care for children below three years. As of August 2013 every child has a legal claim to a slot in a publicly subsidized childcare institution after the first birthday. ${ }^{6}$

The most prominent policy reform is the parental leave reform introduced in 2007. Before implementation of this new reform, families with a new born child were paid a cash benefit amounting to 300 Euro per month for a maximum period of 24 months (chosen by most parents), or 450 Euro per months for a period of 12 months, if at least one parent did not work more than 30 hours per week. This benefit, Erziehungsgeld, was means tested at the household level. Less than $50 \%$ of the families with new born children were eligible due to the income test.

Starting in 2007, the new parental leave benefit, Elterngeld, replaced Erziehungsgeld. Paid for a shorter period of time - 12 months if only one parent takes leave or 14 months if both parents take leave - Elterngeld is not means-tested on household income. The benefit awarded to parents depends on their earnings prior to birth, replacing $67 \%$ of previous net earnings, not

\footnotetext{
${ }^{6}$ In the same period, also the supply of afternoon care for school-children has been increased dramatically by the large expansion of all-day schools (see Beblo et al., 2005; Marcus et al., 2013).
} 
to exceed 1,800 euro per month. The minimum amount Elterngeld awarded is 300 Euro per month, which is equivalent to the monthly benefit paid under the previous Erziehungsgeld.

Thus, the financial incentives induced by this reform differ between high- and low-income mothers as well as between the first and second year after giving birth. Figure 2 shows the amount of parental leave benefits paid to mothers with a monthly gross labor income of 3000 Euro (high income) and 1000 Euro (low income) respectively, before and after the introduction of the reform. For low-income mothers, financial incentives did not change as much during the 12 months after giving birth, however there clearly is the incentive to shorten their leave after their child turns one. Only mothers with a very low income, which entitles them to less that 450 Euro Elterngeld, are incentivized by the reform to return to work in the first year. For mediumand high-income mothers, however, the reform provides incentives to stay at home during the first year after childbirth. These mothers were not eligible for a benefit under the old scheme and can now draw generous benefits amounting to about $67 \%$ of their prior-to-birth earnings.

Figure 2: Benefits paid before and after the reform for exemplary mothers

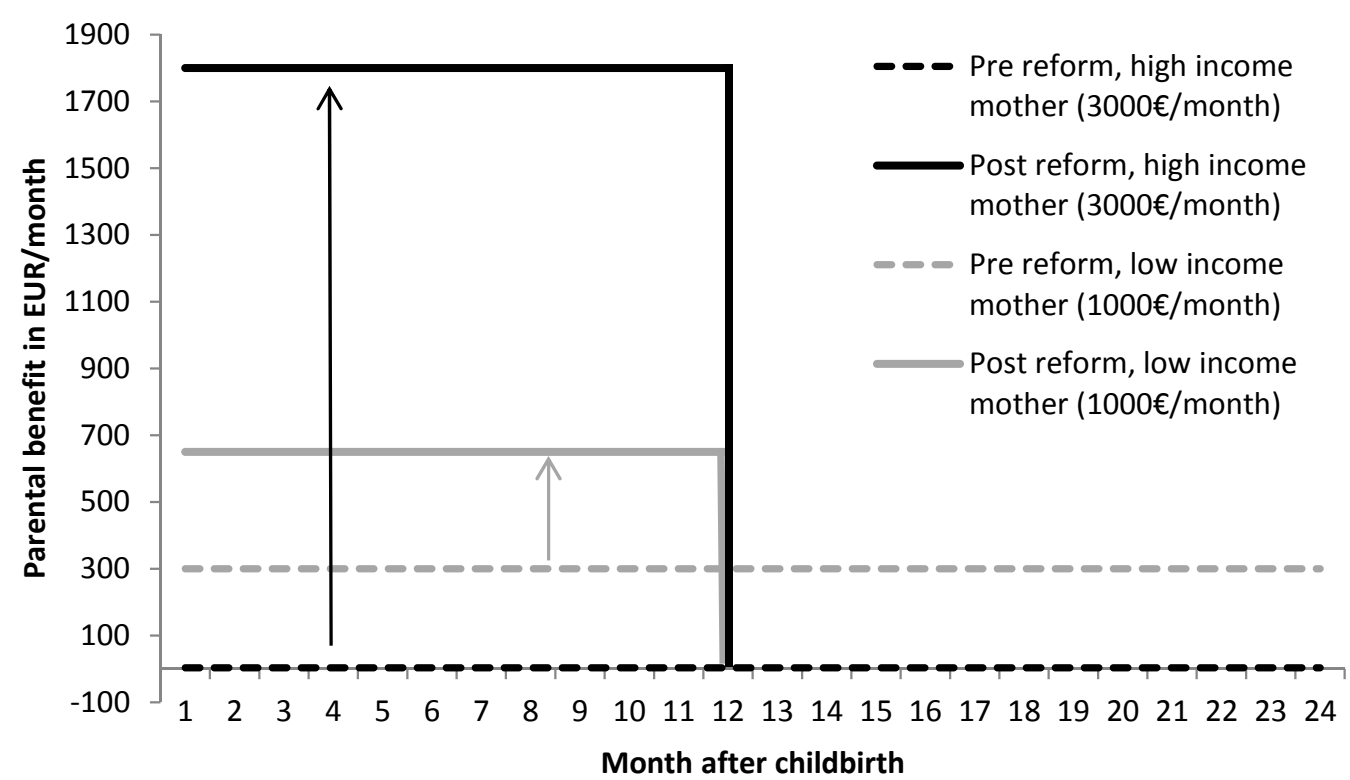

Hypothetical benefits that can be received by married mothers with a net income of 3000 Euro and 1000 Euro per month respectively, based on the online benefit calculator of the Federal Ministry of Family Affairs, Senior Citizens, Women and Youth. https://www.familienwegweiser.de/Elterngeldrechner/index.xhtml, accessed July 20, 2014.

By setting strong incentives to interrupt working by staying at home for (exactly) 12 months, the introduction of the Elterngeld set an institutional norm that children should be cared for by their parents at home until their first birthday. 
Norms regarding parental leave still differ greatly between East and West Germany. Before German reunification in 1990, East German mothers were much less likely to be out of the labor force or work part-time than West German mothers (see Rosenfeld et al., 2004). In East Germany, parental leave benefits were paid for one year, called the Geburtsjahr, and public childcare was generally available. In West Germany, maternal labor supply was comparatively low and, by family policy, mothers were encouraged to stay at home or work part time. After reunification in 1990, social norms regarding maternal labor supply converged with both longer employment interruptions and part time employment becoming more common in the East. We argue that the East German Geburtsjahr created a social anchor point that prevailed after reunification despite the increasing convergence of social norms. This is supported by our finding, displayed in Figure 3, that it was more common in East Germany to return to work between 11 and 15 months after giving birth. However, in West Germany it was common before the 2007 parental leave reform - for children to be cared for at home until they were old enough for Kindergarten at three years of age. Even though this was the leading role model and the expectation of the majority, 25-30\% of mothers with young children did not interrupt employment significantly (see John and Stutzer, 2002). This was particularly true for mothers with higher income and education (see Weber, 2004). Since 2007, however, Elterngeld provides strong financial incentives to interrupt market work for the 12 months following childbirth, particularly for this group.

Figure 3: Hazard rates, by length of parental leave spell in full months, in East and West Germany, 2000 and 2006

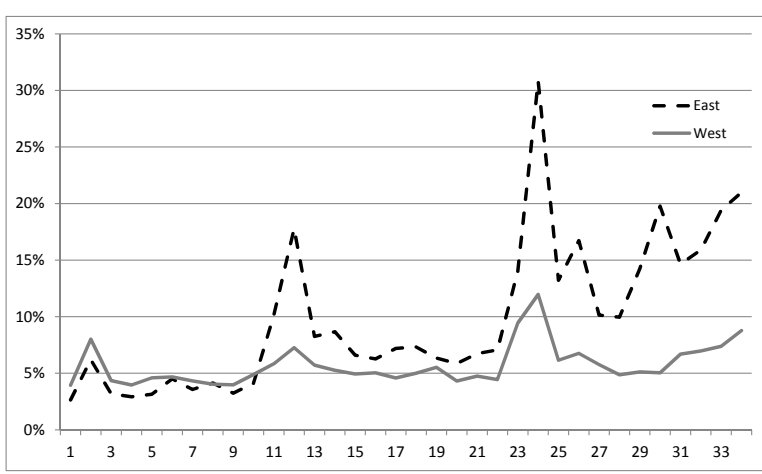

(a) Low income

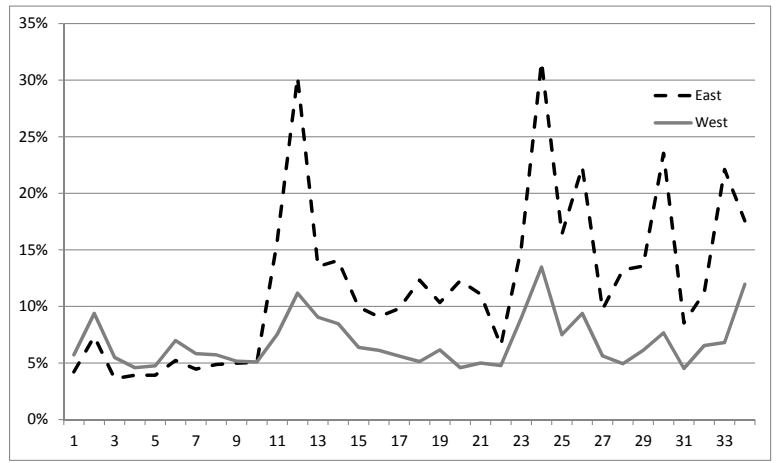

(b) High and medium income

Source: LIAB; based on all mothers who gave birth between 2000 and 2006, who returned to work within 36 months. The income threshold corresponds to a gross labor income of about 1800 Euro per month.

\subsection{Employment effects of the parental leave benefit reform}

A graph of the hazard rates of mothers whose children were born before and after the reform, displayed in Figure 4, reveals that there are peaks after the mandatory maternity leave period of 2 months and then again at both 12 and 24 months. It can also be seen that with the introduction of the Elterngeld, mothers became much more likely to exit parental leave after 12 
months and less likely to return to work during the first 10 months. This is especially true for medium- and high-income mothers (see Figure 4b).

Figure 4: Hazard rates, by length of parental leave spell in full months, before and after the parental leave benefit reform

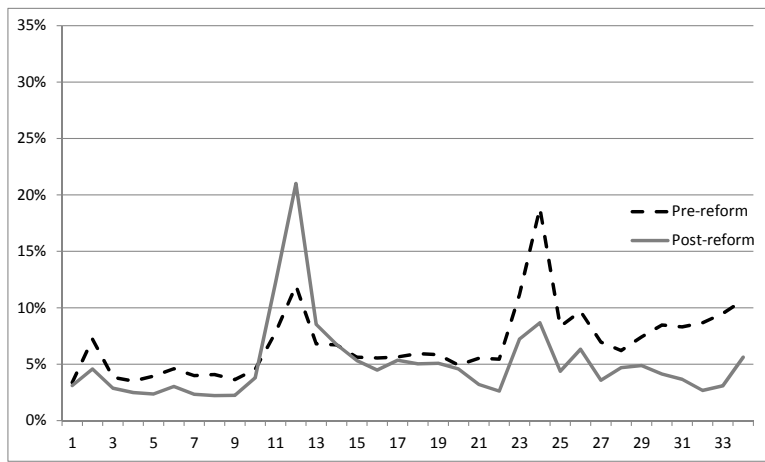

(a) Low income

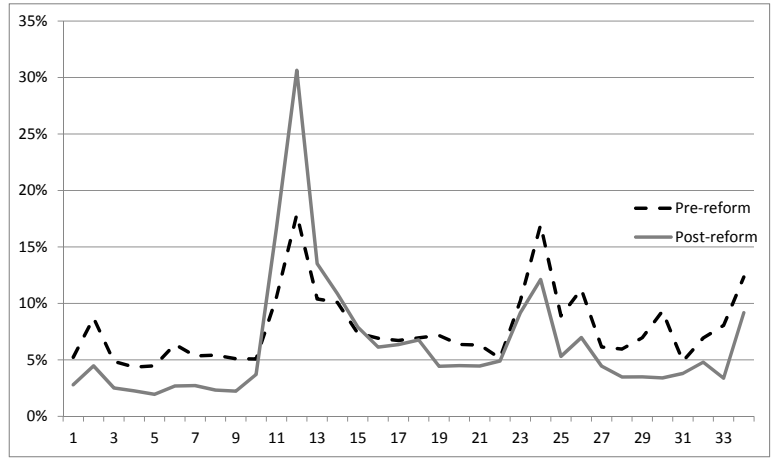

(b) High and medium income

Source: LIAB; based on all mothers who gave birth between 2000 and 2009, who returned to work within 36 months. The income threshold corresponds to a gross labor income of about 1800 Euro per month.

Based on different methods and data-sets, several studies analyze the causal relationship between the parental leave benefit reform of 2007 and the development of maternal employment over time. As expected, Kluve and Tamm (2013), Kluve and Schmitz (2014) and Geyer, Haan, and Wrohlich (2015) find that the probability that mothers return to work during the 12 months following childbirth has declined, in particular for high-income mothers, as a result of Elterngeld being introduced. Furthermore, Geyer et al. (2015), Bergemann and Riphahn (2015), and Kluve and Schmitz (2014) find that the employment of mothers who gave birth after the reform was implemented generally increases after the first 12 months compared to employment of mothers who gave birth before the reform.

Kluve and Schmitz (2014) analyze not only the effect of the Elterngeld introduction on the labor supply of mothers during the first and second year following childbirth but also on the third to fifth year after childbirth. They use a regression discontinuity framework in order to identify the causal effect of the Elterngeld on maternal employment decisions. Based on data from the German Microcensus, they find a large and significant increase in the employment rate of mothers with three to five year old children. However, the authors can only speculate about the mechanism that explains this "causal" (in a statistical sense) effect of the Elterngeld. Since financial incentives did not change in the third or fourth year after giving birth, the behavioral response cannot be explained by standard economic theories. As a possible explanation, the authors suggest that the new parental leave benefit changed social norms. Bergemann and Riphahn (2015) also analyze the short- and medium-term maternal employment effects of the 2007 parental leave reform. They show that employment of young mothers increases and the average duration of the employment interruptions declines. The authors argue that a change in social norms might partly explain the strong employment effect of the reform; in particular they 
show that mothers who may be more likely to be restricted by social norms, such as mothers living in the countryside, living in West Germany, or those with an external locus of control show a stronger response to the reform.

Thus, the empirical findings concerning the 2007 parental leave reform in Germany find that the reform induced mothers to stay at home for the first year after childbirth, but increased the likelihood of maternal employment thereafter. Moreover, empirical findings show that the employment of mothers has changed more than can be explained by financial incentives alone. Some authors speculate that the reform changed social norms concerning the labor supply of mothers with young children. However, a formal test of this hypothesis is, so far, missing. In the next section, we outline how we use the introduction of Elterngeld as an instrument for the identification of peer effects with respect to the labor supply decisions of mothers with young children.

\section{Methodological Approach}

\subsection{Identifying Peer Effects}

The identification of social interaction is challenging because there are several explanations as to why members of a social group behave similarly or exhibit common characteristics. Manski (1993) distinguishes three types of effects that can explain why researchers observe similar outcomes of individuals belonging to the same group. The first is the endogenous effect or peer effect, which we aim to identify. Endogenous effects measure the influence of the decisions of the relevant peer group on individual decisions. The second explanation is concerned with contextual effects, meaning that the individual is influenced by the exogenous group characteristics. The third explanation originates from correlated effects, which means that individuals belonging to the same group tend to behave similarly because they share unobserved characteristics. Correlated effects can be distilled into two challenges to the identification of peer effects: endogenous group formation and correlated unobservable characteristics due to common shocks. The specific challenges associated with the identification of peer effects in the context of labor supply of mothers with young children can be summarized as follows:

- Peer effects are difficult to identify in the case of correlated effects, which are confounded by unobserved variables that are correlated among women who belong to the same social group. Often it cannot be excluded that contextual factors, such as workplace conditions, affect the decisions of employees. Imagine, for instance, a manager who openly supports women who want take parental leave. This would yield longer average duration of leave spells within a group, which could be incorrectly interpreted as a peer effect.

- The endogeneity of social networks, due to sorting into an occupation or firm based on unobservable preferences and firm characteristics, poses another challenge for identification. For example, if women with strong preferences for leisure sort into specific firms 
and occupations that signal family-friendliness and are more likely to take long parental leaves, then peer effects are likely to be overestimated.

- Another challenge associated with the identification of social interaction effects stems from the simultaneity of interactions within a social group. This, it is not possible to determine whether an action is the cause of, or the result of, peer influence.

Several papers focus on the theoretical identification of interaction effects in social groups and networks. For example, Blume et al. (2010) address the problems of reflection, self-selection into social groups, and correlated unobservable group characteristics, in the context of the identification of linear, spatial and discrete choice models with social interaction. Furthermore, Brock and Durlauf (2001), Bramoullé, Djebbari, and Fortin (2009), and Blume, Brock, Durlauf, and Jayaraman (2013) formulate conditions under which economic models with social interactions are identified. Most importantly, the researcher must know the structure of the social network and individual data on the behavior of the members of the social network must be available. In most cases, the natural exclusion restriction induced by the structure of a social network enables the identification of the model. However, data with a known network structure are rarely available.

Thus, several studies assume that social interaction with respect to labor supply takes place within observed groups, including geographic neighborhoods (e.g. Weinberg et al., 2004; Maurin and Moschion, 2009) and family networks (e.g. Del Boca et al., 2000; Dahl et al., 2014; Neumark and Postlewaite, 1998; Nicoletti et al., 2016). We focus on the workplace as the relevant social network. This is based on the assumption that workplace peers matter for decisions regarding employment behavior. There are several studies suggesting that peer effects at the workplace play an important role. Hesselius (2009) shows that peer-effects also exist in the context of absenteeism; Mas and Moretti (2009) focus on workplace peer effects in the context of productivity of cashiers for a large grocery chain, while Cornelissen et al. (2013) use linked employer-employee data to estimate the effect of the long-term quality of a worker's peers (measured by the average wage fixed effect of coworkers in the same firm and occupation) on worker's wage.

Given the identification challenges, empirical studies employ sophisticated strategies to identify peer effects. The use of natural experimental approaches is an increasingly popular way to identify peer effects. For example, Brown (2013) analyzes the retirement decisions of teachers using a reform that affected the retirement age of Los Angeles Unified School District (LAUSD) school teachers. She is able to identify peer effects among teachers of the same schools using random variation in the age composition between LAUSD schools.

We use a quasi-experimental research design similar to Dahl et al. (2014), who estimate peer effects among brothers and coworkers in the context of paternity leave take-up in Norway. The problems of correlated effects, reflection, and endogenous group membership are avoided by using a quasi-natural experiment exploiting variations in the costs of paternity leave induced by a family policy reform. They find that coworkers and brothers are substantially more likely 
to take paternity leave if their peer was induced to take up leave by the reform. An analysis of the channels of social interaction suggests that information transmission regarding costs and benefits is most likely driving the peer effects. Furthermore, the authors find that peer effects are likely to generate "snow-ball" effects over time, i.e. the effects on paternity leave take-up are magnified over time due to an increasing share of fathers affected by the reform, who in turn interact with other fathers and so on.

\subsection{Empirical Strategy}

To overcome the identification challenges mentioned above, we employ an instrumental variable research design that exploits the quasi-random variation in maternal leave spells due to the introduction of the new Elterngeld in January 2007. The parental leave benefit reform encourages, in particular, high-income mothers to stay at home during the first 12 months following childbirth and to benefit from the high income replacement rates under the new Elterngeld. This creates a discontinuity in the fractions of working mothers in the first year after childbirth. In this analysis, we focus on the reform-effect on the behavior of mothers during the first 12 months following childbirth. ${ }^{7}$

Our whole sample consists of mothers, referred to as coworkers, who gave birth on or after July 1, 2007, but on or before December 31, 2009. The coworkers must have a peer who gave birth sometime between July 1, 2006, and June 30, 2007. The sample is then divided into two groups, the control group consisting of those whose peer gave birth prior to the reform's implementation and the treatment group consisting of those who peer gave birth after its implementation. The reform-induced discontinuity is exploited using an instrumental variable research design. Thus, the treatment and comparison groups differ only in whether their peers gave birth before or after the reform. This is illustrated (for a simplified world with two groups) in Figure 5. In both groups we observe only one birth within the reform window. Peer 1 in group 1 gives birth before the reform cutoff-date, and Peer 2 in group 2 gives birth after the cutoff. Consequently, Coworker 1 and Coworker 2, who both give birth after the reform was introduced, vary only in their exposure to peers who gave birth at different points in time.

Figure 5: Sampling and identification

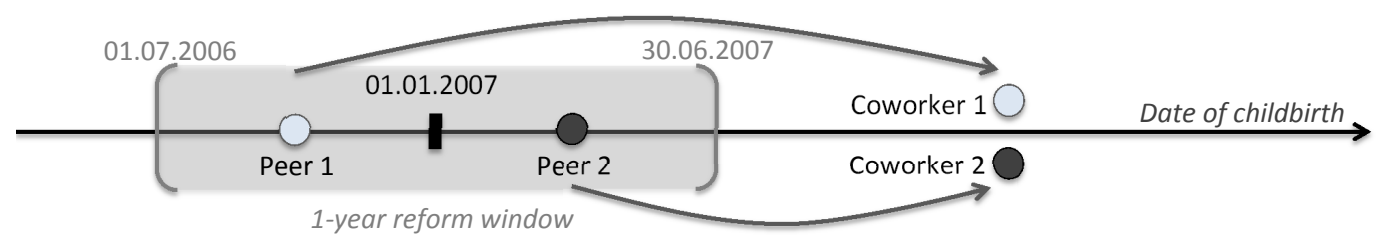

One challenge is that an individual may be affected by several peers. Thus, it is necessary to not just specify a window around the cutoff date, but also to the treatment assignment

\footnotetext{
${ }^{7}$ We plan to extend our analysis to the second year as soon as more recent waves of the LIAB become available.
} 
variable in cases where the coworker-mother had more than one peer giving birth in the window around the cutoff. For large peer groups, our research design has little power because with an increasing time-window around the reform date, the variation in exposure decreases. One specification that sidesteps these issues is to consider peer groups where there are one or more peer mothers in the reform window, but only if they gave birth on the same side of the reform. In an alternative specification, we use the ratio of children born after the cutoff to the total number of children born in a window around the reform as an instrumental variable. We present estimation results from several alternative sample specifications in Section 5.2.

The estimation of the peer effect is made using a two-stage least squares estimator (2SLS), where the reform-induced discontinuity is employed as an instrument to estimate the effect of peer mothers on their coworkers. The problem can be described as a system of two simultaneous equations, where the dependent variables of the first and second equation are the average maternal leave decisions $\left(\bar{y}_{P g}\right)$ of all peer mothers in group $g$, and their coworkers' individual outcomes $\left(y_{C g}\right)$ respectively. Our outcome of interest is a binary variable that equals one if the mother does not return to work within the first 10 months following childbirth. In the first stage, average peer outcome $\bar{y}_{P g}$ in peer group $g$ is regressed on the binary instrumental variable $z_{g}$, which is equal to one if peer mothers' children were born after the reform.

$$
\text { First stage: } \bar{y}_{P g}=\alpha_{0}+W_{g}^{\prime} \alpha_{1}+\lambda z_{g}+\epsilon_{P g}
$$

Since the policy reform $z_{g}$ is exogenous, the reform effect on peer leave behavior $\lambda$ can be identified using a linear regression of average peer maternal leave decisions $\bar{y}_{P g}$, on the treatment variable $z_{g} \cdot{ }^{8}$ To balance observable differences between treated and non-treated mothers, we include individual, group and firm characteristics $W_{g}$ in both equations in some specifications. The results from the first stage are then used to estimate the peer effect $\hat{\delta}$ in the second stage (Equation 2). In the second stage regression, we estimate the probability that a coworker mother stays at home at least 10 months following childbirth $\left(y_{C i g}\right)$, including the first stage fitted values $\hat{\bar{y}}_{P g}$.

$$
\text { Second stage: } y_{C i g}=\beta_{0}+W_{g}^{\prime} \beta_{1}+\delta \hat{\bar{y}}_{P g}+\epsilon_{C i g}
$$

The treatment effect, $\delta$, is the local average treatment effect (LATE) of the reform induced employment interruption decision of the peer mothers on their coworker's maternal leave decisions. It is important to note that the LATE is not equal to the average treatment effect on the treated (ATT), which is equal to a weighted average of the effects on the subpopulations of always-takers and compliers, while the LATE measures the effect on the subpopulation of compliers. As common in the literature, we can only identify the LATE, not the ATT. In this context, compliers are those mothers who have peers who stayed at home throughout the first 10 months after childbirth in response to the parental leave benefit reform, and would not have done so in ab-

\footnotetext{
${ }^{8}$ As a specification test, we include a function of the date of birth of the peer mothers' child, equal to $f\left(x_{P g}\right)=x_{P g}$, in the first stage regression to account for a (linear) time-trend in outcomes. However, while including peer mother date of childbirth does not change the point estimates, it does decrease efficiency. Therefore, we do not include $f\left(x_{P g}\right)$ in our baseline specification.
} 
sence of the reform. Consequently the LATE is equal to $\delta_{L A T E}=E\left[y_{C i g}^{(1)}-y_{C i g}^{(0)} \mid y_{P g}^{(1)}>y_{P g}^{(0)}\right]$, where $y^{(1)}$ and $y^{(0)}$ are the potential outcomes for treated and untreated individuals, or groups, respectively.

In the case of a single binary instrument, the 2SLS estimator is equivalent to a Wald estimator, which is equal to the reduced form estimate of the effect of the policy change on coworkers leave spells divided by the jump in peer outcomes at the date of the policy change:

$$
\delta_{L A T E}=\frac{E\left[y_{C i g} \mid z_{g}=1\right]-E\left[y_{C i g} \mid z_{g}=0\right]}{E\left[y_{P g} \mid z_{g}=1\right]-E\left[y_{P g} \mid z_{g}=0\right]}
$$

The reduced form effect $E\left[y_{C i g} \mid z_{g}=1\right]-E\left[y_{C i g} \mid z_{g}=0\right]$ can be interpreted as the intention to treat effect (ITT) of having a peer mother who gave birth after the reform on the coworkers' probability to stay at home for at least 10 months following childbirth.

Our empirical strategy yields consistent estimates of the LATE if several identifying assumptions are met. The first assumption is independence of the instrumental variable and potential outcomes. Peer mothers have to be as good as randomly assigned to the treatment group, receiving the new parental leave benefit, and the comparison group exposed to the previous regulation within a window around the reform. ${ }^{9}$ For this to be true, we need to assume that individuals are not able to control the treatment assignment variable. Assuming that the timing of birth can only be influenced within a small time window, we can avoid cases where the date of birth is purposefully delayed by dropping observations very close to the first of January 2007. While mothers may have influenced the date of childbirth around the cutoff, it is very unlikely that mothers pre- or postponed childbirth for more than two weeks (see Tamm, 2013). To be certain, we drop all birth events that occur two weeks before and after the cutoff-date from our sample. Mothers who give birth before and after the reform may still differ due to selective fertility in anticipation of the reform. For example, high-income mothers might have delayed pregnancy or even decided to have a child due to the new generous parental leave benefits. ${ }^{10} \mathrm{We}$ argue that before September 2006 there was no definitive knowledge that the policy would be implemented. The legislative process that led to the reform proceeded rapidly. The government coalition agreed on the reform only in May 2006, and the law passed parliament in September 2006. Consequently, most children born during the six months before and after January 1, 2007, were conceived before their parents knew that the reform would be in place by the time of birth (Kluve and Schmitz, 2014). Even if the reform encouraged some women to get pregnant after September 2006, their babies were unlikely to be born before July 1, 2007.

Mothers who give birth in the second half of 2006 can also differ from mothers who give birth in 2007 for reasons unrelated to the parental leave benefit reform. The seasonality of births and the existence of contemporaneous family policy reforms may result in differences in the

\footnotetext{
${ }^{9}$ The 2007 parental leave benefit reform is used as a natural experiment in several evaluations of the policy (Kluve and Tamm, 2013; Kluve and Schmitz, 2014; Bergemann and Riphahn, 2011; Wrohlich et al., 2012; Bergemann and Riphahn, 2015).

${ }^{10}$ Raute (2014) finds evidence for a positive fertility effect of the 2007 parental leave benefit reform starting 9 months after the law was passed.
} 
characteristics of mothers. In particular, several child care reforms carried out between 2005 and 2007 successively increased the availability of subsidized child care for children younger than three, ${ }^{11}$ which had sizable employment effects on mothers (see Geyer et al., 2015). We show in Table 6 of the Appendix that most observable characteristics of peer mothers in the treatment and the comparison group do not differ significantly. Given that peer mothers were quasi-randomly assigned to the treatment group, it can be assumed that their coworkers do not differ except in their exposure to peers who gave birth on different sides of the reform cutoffdate. To strengthen the argument, a comparison of treated and non-treated coworkers can be found in Table 7 (Appendix).

While most covariates are balanced across treatment and comparison groups of both peer mothers and their coworkers, a closer look at Table 6 reveals that the treatment group has more observations. In other words, the sample of mothers who gave birth from January to June 2007 is larger than the sample of mothers who gave birth between July and December 2006. Our identification strategy is threatened if this is due to selective fertility around the introduction of the reform, or if mothers who give birth in the first half of the year differ from those who give birth in the second half of the year for other reasons. We repeat our sampling procedure for seven hypothetical reform dates on January 1st of the respective years from 2002 to 2009 to see whether the year around the actual reform (2007) differs from previous and later years. The distribution of births per month within the different samples, displayed in Figure 8, shows that there were comparatively few births in the second half of 2006. However, the empirical evidence does not suggest a non-random deviation compared to previous and later years. Consequently, we assume that the difference in the number of observations between treatment and comparison groups is due to a random variation in births.

Another identifying assumption is the exclusion restriction, which requires that the instrument operates through a single known channel, i.e. coworker outcomes are not affected by the parental leave benefit reform through channels other than peer behavior. All coworker outcomes are observed for mothers who give birth after the reform was implemented. Therefore, it can be assumed that whether a peer mother gave birth before or after the reform had no effect on coworkers' behavior other than through peer behavior. Another necessary assumption for the validity of our research design is that the reform effect is monotone, i.e. that no mother is more likely to get back to work within 10 months after giving birth as a response to the reform. This is granted because the parental leave benefit reform did not reduce benefits for any mother in our sample, which excludes low-income mothers, during the first 12 months after childbirth; for most mothers, benefits increased. This increase in benefits was particularly high for our sample of medium- and high-income mothers.

Our empirical strategy is able to circumvent the standard identification issues associated with social interaction effects. The problem of simultaneity is solved by the time dimension, which excludes the possibility of peer decisions being influenced by their coworkers who gave birth afterwards, assuming that mothers do not coordinate their leave beforehand. Bias due

\footnotetext{
${ }^{11}$ For an overview of the child care reforms, see Spieß (2011).
} 
to correlated effects and endogenous group formation can be avoided because the parental leave reform is orthogonal to unobserved characteristics and therefore treated and non-treated mothers differ only in their exposure to peers who gave birth before and after the parental leave reform respectively. Consequently, we argue that the estimated effect can be attributed solely to the influence of peer mothers' behavior.

\section{Data}

The empirical analysis is based on administrative Linked Employer-Employee Data from the IAB (LIAB). ${ }^{12}$ The LIAB includes individual employment histories generated from administrative data provided by firms and social security data from 1993 to 2011. Individual employment histories are merged with annual IAB establishment panel data, which includes detailed firm characteristics such as developments in employment (production, turnover, working hours, investment, capacity utilization), and demand for personnel and labor expectations (vacancies, open positions, fluctuations, establishment employment policies). In addition, the LIAB includes information on firms' technology, organization structure, determinants of productivity, firm size and industry. We merged the LIAB with regional information on childcare coverage, population density, and unemployment rates (INKAR, 2015).

When estimating peer effects, the challenge is to find a data set that contains micro data on an individual's social network. The researcher has to know (or assume to know) the relevant reference group. One of the main advantages of the LIAB is that it includes a large number of firms and individuals (in 2007, we observe 5,364 firms), and that the full network of employees working at the same firm can be identified. Therefore, this data set has already been used by several studies to analyze peer effects in different contexts. For example, Cornelissen et al. (2013) use the LIAB to analyze peer effects on wages, and Pink et al. (2013) study workplace peer effects on fertility.

A disadvantage of the LIAB data, however, is that parental leave spells and events of childbirth are not directly observed. We only observe gaps in employment histories, which could also be due to periods of military service, illness, disability, or early retirement. However, Schönberg (2009) shows that it is possible to identify maternal leave spells and events of childbirth with sufficient accuracy by using the starting point and duration of employment interruptions. ${ }^{13}$ Employment interruptions of at least 14 weeks are likely to be maternity leave spells due to the obligatory maternity leave period of 6 weeks before and 8 weeks after childbirth. The likelihood that an employment interruption is due to childbirth is increased by restricting the sample to women between the age of 18 and 40. Following Schönberg and Ludsteck (2014); Dustmann and Schönberg (2011), we approximate the child's date of birth as six weeks after the mother

\footnotetext{
${ }^{12}$ Data access was provided via on-site use at the Research Data Centre (FDZ) of the German Federal Employment Agency (BA) at the Institute for Employment Research (IAB) and subsequently remote data access.

${ }^{13}$ Schönberg (2009) shows that after some appropriate restrictions are imposed, at least 90 percent of leave spells in the data are due to maternity leave in West Germany. The child's birth month is correctly estimated for at least 70 percent, and over- or underestimated by one month for about 25 percent of mothers.
} 
went on leave, which leads to some measurement error in the child's month of birth. ${ }^{14}$

As previously noted, and given our identification strategy, the sample is restricted to those female coworkers who gave birth after July 1, 2007, and before December 31, 2009, conditional on these mothers having a peer who gave birth sometime between July 1, 2006 and June 30, 2007. The peer had to belong to the same peer group as determined by occupation and firm identifier. For small firms with 99 or fewer employees, peer groups are formed only by the firm identifier. Occupations are defined using two-digit occupational groups according to KldB (Bundesanstalt für Arbeit, Nürnberg, 1988), which summarizes related occupations into 86 larger groups. Firm identifiers differ by establishment.

The sample selection proceeds as follows. First, employed mothers who give birth in a oneyear window around the parental leave benefit reform (January 1, 2007) are marked as potential peer mothers. We observe 4375 births in the reform-window. In the next step, we group all women who work in the same firm and occupation and then count the number of births before and after January 01, 2007 within the reform-window. In our baseline specification, we keep only those peer groups where there are either births before or after the reform, dropping all groups where there are births on neither or both sides of the cutoff-date. Most groups (about 83\%) are lost because no woman gives birth within the reform-window. We lose another 2845 birth events because there is at least one birth before and one after the reform within the specified window. The number of potential peer mothers is further reduced to 1413 by dropping all groups where a birth event falls within the 28-day window around the reform date because of potential measurement error in birth dates and concerns about manipulation of the date of childbirth. Thereafter, we identify all coworkers of potential peer mothers, who work in the same firm and occupation, and mark those who give birth after their peers and after the reform-window. One limitation is the right-censoring of the observed maternal leave spells. When looking at the fraction of mothers returning within the first 12 months following childbirth, we have to drop all observations of birth events that occur after December 31, 2009 because our observation periods ends on December 31, 2010. Furthermore, we include only the first observed birth if the same coworker gives birth more than once. In the next step, we generate the treatment assignment variable (peer mothers' date of childbirth) by taking the latest birth within a group and window, and define peer outcomes and characteristics by taking the mean if there is more than one peer mother.

Because the parental leave benefit reform had heterogeneous effects on different income groups, we divide the sample of coworkers by peer income. ${ }^{15}$ We drop peer groups with a low average income to exclude the possibility that peer mothers' employment decreased in the first year as a response to the reform. After limiting our sample to peer mothers in the upper two-thirds of the income distribution (monthly income ${ }^{16} \geq 1814$ Euro), and their coworkers, we

\footnotetext{
${ }^{14}$ We specifically thank Dana Müller and Katharina Strauch for their Stata dofiles and assistance.

${ }^{15}$ Note that the sample is divided by peer, not coworker, income because peer mothers are heterogeneously affected by the parental leave benefit reform. There is no restriction on coworker income, however, the coworker income distribution is very similar to the peer income distribution due to the definition of peer groups.

${ }^{16}$ Monthly gross labor income is computed as an average over the last 12 months before beginning of the
} 
are left with a sample of 488 peer mothers and 1340 coworkers.

From the 12,069 birth events observed between July 2007 and December 2009, we are left with a sample of 1340 coworkers, which amounts to $11 \%$ of all observed births over that time period (see Table 8 for an overview of the sample sizes of the baseline specification and several alternative sample and treatment assignment variable specifications). The resulting sample is not representative of all women who gave birth between July 2007 and December 2009. Table 9 compares the characteristics of women in our baseline sample to all women in the LIAB who gave birth in the same time period. Due to the sample selection by income, it is not surprising that women in our sample have a higher average income and are more likely to be highly educated (tertiary degree). Furthermore, women in our sample have more overall work experience and are less likely to be unemployed or part-time employed. The selection of peer groups with at least one birth event in the one-year reform window around the reform results in a much larger average firm size within the sample. Descriptive statistics of all other sample specifications can be found in Table 10 in the Appendix.

\section{Results}

\subsection{Baseline results}

Women who work in the same firm and occupational group may have similar unobserved characteristics and preferences regarding employment and family-life. Consequently, parental leave behavior may be correlated within a group of coworkers regardless of peer effects. In order to single out the peer effect, we employ a two-staged least squares (2SLS) regression using whether or not peer mothers gave birth after the parental leave benefit reform as the instrumental variable for the endogenous peer behavior.

The first stage regression estimates the reform effect on the probability that a peer mother stays at home for at least 10 months after giving birth. It can be seen graphically in Figure 6a that the fraction of mothers staying home during the first 10 months increased steeply by about 20 percentage points. A comparison of pre- and post-reform means reveals that the outcome variable increased from $56.3 \%$ to $76.0 \%$ for the group of medium- and high-income peer mothers in our sample (displayed at the bottom of Table 1). Consistent with the descriptive evidence and findings of previous literature, we find that the reform significantly increased the likelihood of high-income mothers to stay at home during the first year. Our estimates of a 21.5 percentage point increase (see column 1 in Table 1 ) in the probability to stay home in the first 10 months exceed previous results, which is due to the specific sample used in this analysis (i.e. mothers who were employed before giving birth and who have a relatively high income). Including various control variables lowers the point estimate of the reform effect only marginally. Significant first stage coefficients and an F-statistic above 10 alleviate concerns about a weak instrumental variable.

maternity leave period. 
Figure 6: Fraction of peer mothers (a) and their coworkers (b), who stay at home for at least 10 months, by average peer month of childbirth

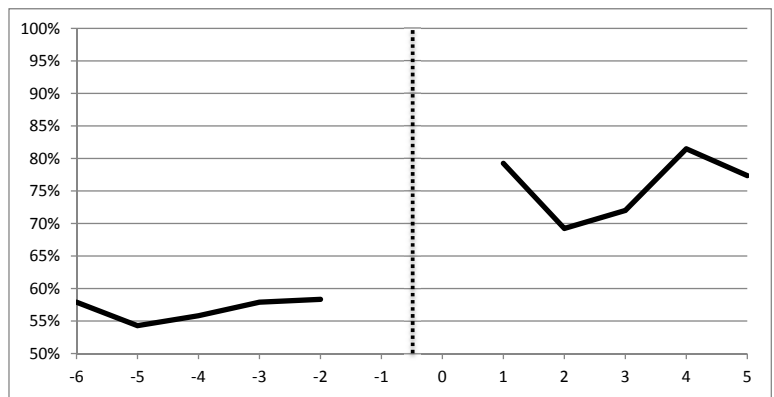

(a) First stage (peers)

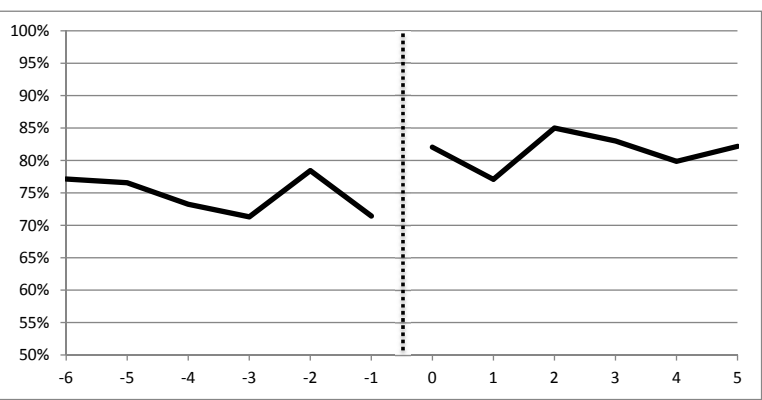

(b) Reduced form (coworkers)

The figure is based on our own analysis using the LIAB. Fractions are calculated out of coworkers/peers in the sample, by average peer months of childbirth in distance to the reform $(01 / 2007=0)$. Due to very few observations for the months around the reform, we drop December 2006 and January 2007 from Figure (a).

Figure $6 \mathrm{~b}$ shows the average fraction of coworkers not returning within 10 months by average peer date of childbirth. The increase around January 2007 is comparable to the difference between the means in coworkers outcomes by peer mothers' date of childbirth displayed at the bottom of Table 1. We estimate the reduced form effect of having a peer mother who gave birth after the reform on the coworkers' probability to stay at home for at least 10 months after childbirth. This can be interpreted as intention to treat (ITT) effect. We find that the ITT is positive and significant, amounting to 6.8 percentage points without covariates and 5.3 percentage points if we include covariates (see Table 1), suggesting that having a peer who gave birth before or after the reform has an important impact on coworkers' parental leave behavior.

In the simple case of a single binary instrument, the peer effect can be computed by dividing the reduced form (ITT) by the first stage estimate. As shown in Table 1, we find a significant peer effect of about 28.2 to 31.5 percentage points, i.e. a mother is about 30 percentage points more likely to stay at home during the first 10 months if her peer mothers decide to do so as a response to the parental leave benefit reform. Including linear trends in the date of childbirth and several control variables does not change the results substantially. Note that in cases where a mother has several peers who gave birth in the one-year window around the reform, the treatment variable can lie between zero and one because it is defined as the average peer outcome. The peer effect is estimated as the effect of a change from zero to one, i.e. the effect of all peer mothers deciding to stay at home in the first year compared to none. 
Table 1: First stage, reduced form (ITT) and peer effect (LATE) 2SLS-estimation results

\begin{tabular}{|c|c|c|c|c|c|c|}
\hline$y_{C}$ & \multicolumn{2}{|c|}{ First stage } & \multicolumn{2}{|c|}{ Reduced form } & \multicolumn{2}{|c|}{ Peer effect } \\
\hline$z_{g}$ & $\begin{array}{c}0.215^{* * *} \\
(0.060)\end{array}$ & $\begin{array}{c}0.188^{* * *} \\
(0.058)\end{array}$ & $\begin{array}{c}0.068^{* * *} \\
(0.024)\end{array}$ & $\begin{array}{c}0.053^{* *} \\
(0.025)\end{array}$ & & \\
\hline $\bar{y}_{P}$ & & & & & $\begin{array}{c}0.315^{* * *} \\
(0.116)\end{array}$ & $\begin{array}{l}0.282^{*} \\
(0.148)\end{array}$ \\
\hline$x_{C}$ (Month of childbirth) & & $\begin{array}{c}0.000 \\
(0.001)\end{array}$ & & $\begin{array}{l}-0.001 \\
(0.001)\end{array}$ & & $\begin{array}{l}-0.001 \\
(0.001)\end{array}$ \\
\hline Age at childbirth & & $\begin{array}{l}-0.003 \\
(0.003)\end{array}$ & & $\begin{array}{l}-0.004 \\
(0.003)\end{array}$ & & $\begin{array}{l}-0.003^{*} \\
(0.003)\end{array}$ \\
\hline Peer age & & $\begin{array}{l}-0.011 \\
(0.008)\end{array}$ & & $\begin{array}{l}-0.002 \\
(0.003)\end{array}$ & & $\begin{array}{c}0.001 \\
(0.005)\end{array}$ \\
\hline Prior earnings & & $\begin{array}{c}0.000 \\
(0.000)\end{array}$ & & $\begin{array}{c}0.000 \\
(0.000)\end{array}$ & & $\begin{array}{l}0.000^{*} \\
(0.000)\end{array}$ \\
\hline Peer earnings & & $\begin{array}{c}0.000 \\
(0.000)\end{array}$ & & $\begin{array}{l}0.000 \\
(0.000)\end{array}$ & & $\begin{array}{l}0.000^{*} \\
(0.000)\end{array}$ \\
\hline High education & & $\begin{array}{l}-0.038 \\
(0.045)\end{array}$ & & $\begin{array}{l}-0.004 \\
(0.036)\end{array}$ & & $\begin{array}{c}0.006 \\
(0.036)\end{array}$ \\
\hline Low education & & $\begin{array}{l}-0.084 \\
(0.063)\end{array}$ & & $\begin{array}{l}0.010^{*} \\
(0.052)\end{array}$ & & $\begin{array}{r}0.124^{* *} \\
(0.058)\end{array}$ \\
\hline Peer high education & & $\begin{array}{l}0.025 \\
(0.071)\end{array}$ & & $\begin{array}{l}0.005 \\
(0.035)\end{array}$ & & $\begin{array}{l}-0.002 \\
(0.035)\end{array}$ \\
\hline Peer low education & & $\begin{array}{c}0.265^{* * *} \\
(0.102)\end{array}$ & & $\begin{array}{l}0.006 \\
(0.125)\end{array}$ & & $\begin{array}{l}-0.068 \\
(0.125)\end{array}$ \\
\hline Firm size & & $\begin{array}{c}0.000^{* *} \\
(0.000)\end{array}$ & & $\begin{array}{l}0.000^{*} \\
(0.000)\end{array}$ & & $\begin{array}{c}0.000 \\
(0.000)\end{array}$ \\
\hline Number of peer births & & $\begin{array}{c}-0.050^{* *} \\
(0.020)\end{array}$ & & $\begin{array}{l}-0.014 \\
(0.010)\end{array}$ & & $\begin{array}{c}0.000 \\
(0.011)\end{array}$ \\
\hline Peer group size & & $\begin{array}{c}0.001^{* * *} \\
(0.000)\end{array}$ & & $\begin{array}{l}0.000^{*} \\
(0.000)\end{array}$ & & $\begin{array}{c}0.000 \\
(0.000)\end{array}$ \\
\hline West Germany & & $\begin{array}{c}0.074 \\
(0.061)\end{array}$ & & $\begin{array}{c}0.007 \\
(0.029)\end{array}$ & & $\begin{array}{l}-0.014 \\
(0.034)\end{array}$ \\
\hline Constant & $\begin{array}{c}0.533^{* * *} \\
(0.060)\end{array}$ & $\begin{array}{c}1.016^{* * *} \\
(0.258)\end{array}$ & $\begin{array}{c}0.748^{* * *} \\
(0.019)\end{array}$ & $\begin{array}{c}0.931^{* * *} \\
(0.142)\end{array}$ & $\begin{array}{c}0.580^{* * *} \\
(0.079)\end{array}$ & $\begin{array}{r}0.645^{* * *} \\
(0.250)\end{array}$ \\
\hline \multicolumn{7}{|c|}{$* * * \mathrm{p}<0.01,{ }^{* *} \mathrm{p}<0.05,{ }^{*} \mathrm{p}<0.1$} \\
\hline $\mathrm{N}$ & 1340 & 1336 & 1340 & 1336 & 1340 & 1336 \\
\hline$R^{2}$ & 0.067 & 0.117 & 0.006 & 0.016 & & \\
\hline Adj. $R^{2}$ & 0.066 & 0.108 & & & & \\
\hline Partial $R^{2}$ & 0.067 & 0.047 & & & & \\
\hline Robust $\mathrm{F}(1,310)$ & $13.003^{* * *}$ & $10.609^{* * *}$ & & & & \\
\hline $\begin{array}{l}\text { Pre-mean }\left(z_{P}=0\right) \\
\text { Post-mean }\left(z_{P}=1\right)\end{array}$ & $\begin{array}{l}0.563 \\
0.760\end{array}$ & & $\begin{array}{l}0.748 \\
0.816\end{array}$ & & & \\
\hline
\end{tabular}

Note: The dependent variable $y_{C}$ is defined as an indicator equal to one if the individual does not return to work within 10 months after childbirth. First stage and reduced form regressions include the same control variables as the corresponding 2SLS regression. Standard errors (in parentheses) are clustered on firm level. 
The large magnitude of the estimated peer effect could be due to the specific subgroup for which the effect is estimated. The effects have to be interpreted as local average treatment effects (LATE) of reform-induced changes in peer mothers' parental leave behavior on the leave taking behavior of coworkers. In other words, we cannot identify the average treatment effect on the treated (ATT) because we estimate the effect only for a subpopulation of those coworkers whose peers stay at home during the first 10 months after childbirth if their child is born after the reform, and would have returned to work within 10 months if their child were born before the reform. The LATE can be expected to differ from the ATT because peer effects are likely to be heterogeneous across firms and occupations. For example, we expect peer effects to be larger in the subgroup of compliers, which contains groups where peer mothers respond to the reform, and would have returned early in absence of the Elterngeld. We know from the first stage estimation that the subgroup of compliers amounts to about one-fifth of the total sample. However, we cannot observe the compliers directly because we do not observe counterfactual outcomes. One way to learn more about the group of compliers is to use the variation in the first stage across covariate groups (see Angrist and Pischke, 2009). Dividing the subgroup estimate by the baseline first-stage result yields the relative likelihood that a complier belongs to a certain group. A first stage analysis across covariate groups, displayed in Table 11 in the Appendix, reveals that compliers are more likely to have university education, be in the upper third of the income distribution and work in large and old firms. This is in line with our intuition that compliers have a greater labor market attachment.

\subsection{Robustness and specification tests}

A crucial underlying assumption of our results is the comparability of treated and non-treated individuals. Given our assumption that whether a mother is exposed to peers who gave birth before or after the reform is purely random, treated and non-treated mothers should have the same distribution of covariates. A simple mean comparison of treated and non-treated coworkers (Table 7) points to significant differences in only one variable, namely the number of days employed in the firm. To correct for imbalances, thereby improving the precision of our estimates, we include a number of additional covariates that potentially affect maternal leave decisions in Table 2 .

Including additional control variables on the individual, firm and regional level does not change the results, nor does the inclusion of occupational or industry fixed effects, as can be seen in Table 2. All three estimated parameters, the first stage result, the peer effect given by the LATE, as well as the reduced form effect remain statistically significant and within the same magnitude as in the baseline specification. In the last rows of Table 2, we use the interaction of the treatment dummy with the number of peer births as an instrumental variable in the regressions to account for differences in the intensity of treatment; however, point estimates and standard errors remain similar.

Another set of robustness checks concerns the definition of the sample. While the sample 
Table 2: Inclusion of additional individual, firm and regional characteristics

\begin{tabular}{lccccc}
\hline & First stage & Reduced form & Peer effect & $\mathrm{N}$ & Controls \\
\hline \hline Baseline & $0.215^{* * *}$ & $0.068^{* * *}$ & $0.315^{* * *}$ & 1340 & No \\
& $(0.060)$ & $(0.024)$ & $(0.116)$ & & \\
\hline Additional peer chars (1) & $0.188^{* * *}$ & $0.049^{*}$ & $0.259^{*}$ & 1336 & Yes \\
& $(0.056)$ & $(0.026)$ & $(0.151)$ & & \\
Additional coworker chars (1) & $0.191^{* * *}$ & $0.052^{* *}$ & $0.272^{*}$ & 1336 & Yes \\
& $(0.057)$ & $(0.024)$ & $(0.142)$ & & \\
Firm level covariates (2) & $0.222^{* * *}$ & $0.085^{* *}$ & $0.385^{* *}$ & 779 & Yes \\
& $(0.063)$ & $(0.036)$ & $(0.192)$ & & \\
Regional covariates (3) & $0.164^{* * *}$ & $0.062^{* *}$ & $0.378^{* *}$ & 1295 & Yes \\
& $(0.056)$ & $(0.025)$ & $(0.189)$ & & \\
Occupational Fixed Effects & $0.176^{* * *}$ & $0.057^{* *}$ & $0.322^{*}$ & 1336 & Yes \\
& $(0.059)$ & $(0.025)$ & $(0.165)$ & & \\
Industry Fixed Effects & $0.209^{* * *}$ & $0.062^{*}$ & $0.297^{*}$ & 968 & Yes \\
& $(0.063)$ & $(0.033)$ & $(0.175)$ & & \\
\hline Using interaction of dummy and & $0.028^{* * *}$ & $0.010^{* * *}$ & $0.371^{* * *}$ & 1340 & No \\
number of peer births as IV & $(0.010)$ & $(0.004)$ & $(0.096)$ & & \\
& $0.115^{* * *}$ & $0.037^{* *}$ & $0.327^{* *}$ & 1336 & Yes \\
& $(0.029)$ & $(0.014)$ & $(0.129)$ & & \\
\hline
\end{tabular}

Note: The dependent variable $y_{C}$ is defined as an indicator equal to one if the individual does not return to work within the first 10 months after childbirth. First stage and reduced form regressions include the same control variables as the corresponding 2SLS regression. Standard errors (in parentheses) are clustered on the firm level. Control variables include month of childbirth, age of the mother, prior-tobirth earnings, as well as the education level of both coworkers and peer mothers. Firm size, number of peer births in reform window, peer group size and a dummy for West Germany. Additional individual characteristics (1) include experience, tenure in firm, days in unemployment, part-time employment prior-to-birth and the number of children. Firm level covariates (2) include a dummy for old firms $(>10$ years) and standardized wages, churn rate, median firm income, and the share of female employees, part-time and temporary workers. Regional covariates (3) include district childcare coverage, population density and unemployment rate. 
used for the baseline specification shown in Table 1 consists of groups in which we observe peer mothers giving birth to a child either before or after the reform, Table 3 presents the results from four alternative definitions of the estimation sample.

In order to increase the sample size and, thereby, statistical power, we use all observations with at least one birth in the reform window in sample specification A. To be more specific, in contrast to the previous samples, we keep groups in which we observe peer mothers giving birth on both sides of the cut-off date. This results in a larger sample of 3195 coworkers and, on average, the inclusion of larger peer groups (see Table 9 in the Appendix for descriptive statistics of all sample specifications). In this specification, we use the ratio of peer mothers who gave birth after the reform to the total number of births in the reform-window as instrumental variable affecting average peer behavior. To account for nonlinearities, we include a square of the ratio as additional instrument. We find smaller peer effects using this sample specification, which could be due to the inclusion of larger groups where social interaction between coworkers may be less likely. The disadvantages of this specification are that because we no longer have a single binary instrument we cannot compare treatment and control groups, and the interpretation of first stage and reduced form coefficients is no longer straightforward.

Sample B is specified as the baseline sample, however here we drop all observations with peer births occurring in December 2006 or January 2007 (rather than just a 4-week window around the reform date). Dropping peer groups where there is a birth in a 60-day window around the reform date does not change the results compared to our baseline specification. In our baseline specification, peer groups are defined by firm (establishment) and occupational group. In contrast, we assume that mothers interact with each other across occupational groups in sample specification $\mathrm{C}$, where the whole firm is defined as the relevant peer group. This results in a sample with smaller firms on average, because the sample selection is still conditional on observing births on only one side of the reform cutoff date. We find smaller, insignificant first stage and ITT effects using this specification. In Sample D we restrict the sample to coworkers who gave birth to a child at least 9 months after the last peer mother within the group has given birth to a child in order to make sure that enough time has gone by that the coworkers may observe reactions to the peer's decisions. Reassuringly, point estimates for all three parameters of interest are very similar to the baseline specification.

The main threat to our identification strategy is that mothers may have selected into treatment by timing their pregnancy in anticipation of the parental leave benefit reform. In Section 3.2, we note that it is possible, although unlikely, that mothers anticipated the reform in mid-2006, and reacted by increased fertility in the first half of 2007. By limiting the sample of peer mothers to those who gave birth in an six-month (Sample E) and eight-month window (Sample F) around the reform, we minimize the probability of selected fertility. Reassuringly, we find positive reduced form and peer effects using a shorter window, despite the smaller variation in peer behavior, even though the coefficients are only partly significant.

Finally, we repeat the analysis using a sample without any restrictions on peer income (Sample G). In contrast to our baseline specification, we also include those peer groups where 
the (mean) peer income is in the bottom third of the income distribution. We exclude this group in our baseline specification due to heterogenous reform effects (low income mothers can be induced to return to work earlier due to the parental leave benefit reform) and the implied violation of the monotonicity assumption. The first stage effect disappears when we include all income groups, suggesting that the reform indeed did not induce low income mothers to stay at home for the first year following childbirth. Without a significant first stage, the estimates of reduced form and peer effects are meaningless. 
Table 3: Results from alternative sample specifications

\begin{tabular}{|c|c|c|c|c|c|}
\hline & First stage & Reduced form & Peer effect & $\mathrm{N}$ & Controls \\
\hline \multirow{4}{*}{$\begin{array}{l}\text { A. Using all observations where } \\
\text { there is at least one birth } \\
\text { in the reform window }\end{array}$} & & & $0.223^{*}$ & 3195 & No \\
\hline & & & $(0.110)$ & & \\
\hline & & & $0.200^{*}$ & 3195 & Yes \\
\hline & & & $(0.119)$ & & \\
\hline \multirow{4}{*}{$\begin{array}{l}\text { B. } 30 \text { days donut around } \\
\text { cutoff date }\end{array}$} & $0.223^{* * *}$ & $0.065^{* * *}$ & $0.293^{* *}$ & 1245 & No \\
\hline & $(0.063)$ & $(0.024)$ & $(0.113)$ & & \\
\hline & $0.197 * * *$ & $0.049^{*}$ & $0.247^{*}$ & 1241 & Yes \\
\hline & $(0.061)$ & $(0.025)$ & $(0.144)$ & & \\
\hline \multirow[t]{4}{*}{ C. Peer groups $=$ firms } & 0.103 & 0.033 & 0.315 & 1089 & $\mathrm{No}$ \\
\hline & $(0.071)$ & $(0.027)$ & $(0.296)$ & & \\
\hline & $0.116^{*}$ & 0.034 & 0.296 & 1083 & Yes \\
\hline & $(0.067)$ & $(0.027)$ & $(0.270)$ & & \\
\hline \multirow{4}{*}{$\begin{array}{l}\text { D. Coworker birth at least } \\
9 \text { months after peer birth }\end{array}$} & $0.206^{* * *}$ & $0.070 * * *$ & $0.340^{* * *}$ & 1107 & No \\
\hline & $(0.061)$ & $(0.025)$ & $(0.130)$ & & \\
\hline & $0.169^{* * *}$ & $0.064^{* *}$ & $0.380^{*}$ & 1105 & Yes \\
\hline & $(0.060)$ & $(0.027)$ & $(0.195)$ & & \\
\hline \multirow{4}{*}{$\begin{array}{l}\text { E. Six-month reform-window } \\
( \pm 3 \text { months })\end{array}$} & $0.196^{* * *}$ & $0.046^{*}$ & 0.236 & 1482 & No \\
\hline & $(0.067)$ & $(0.025)$ & $(0.152)$ & & \\
\hline & $0.256^{* * *}$ & 0.028 & 0.111 & 1480 & Yes \\
\hline & $(0.075)$ & $(0.024)$ & $(0.101)$ & & \\
\hline \multirow{4}{*}{$\begin{array}{l}\text { F. Eight-month reform window } \\
( \pm 4 \text { months })\end{array}$} & $0.175^{* * *}$ & $0.047^{*}$ & $0.267^{*}$ & 1438 & No \\
\hline & $(0.054)$ & $(0.024)$ & $(0.157)$ & & \\
\hline & $0.183^{* * *}$ & $0.040^{*}$ & 0.222 & 1434 & Yes \\
\hline & $(0.057)$ & $(0.023)$ & $(0.143)$ & & \\
\hline \multirow[t]{4}{*}{ G. Using all income groups } & 0.112 & 0.023 & 0.202 & 2158 & No \\
\hline & $(0.046)$ & $(0.020)$ & $(0.176)$ & & \\
\hline & 0.086 & 0.011 & 0.130 & 2149 & Yes \\
\hline & $(0.044)$ & $(0.020)$ & $(0.236)$ & & \\
\hline
\end{tabular}

Note: The dependent variable $y_{C}$ is defined as an indicator equal to one if the individual does not return to work within 10 months after childbirth. First stage and reduced form regressions include the same control variables as the corresponding 2SLS regression. Standard errors (in parentheses) are clustered on the firm level. Control variables include month of childbirth, age of the mother, prior-to-birth earnings and education level of both coworkers and peer mothers. Firm size, number of peer births in reform window, peer group size and a dummy for West Germany.

Our results, presented in Table 1, suggest that individual parental leave decisions are substantially influenced by the parental leave behavior of coworkers working in the same firm and 
occupation. If these results are truly peer effects, we expect both first stage and reduced form effects to disappear when we center the reform-window around a date when there was no change in the parental leave benefit regime. To test this hypothesis, we create a placebo-sample by recentering the reform-window around January 1, 2006, using the same sample selection procedure as in our baseline specification. The results are displayed in Table 4. A significant first stage would hint at a difference in parental leave behavior of women who give birth in the first vs. the second half of a year (in this case January to June 2006 vs. July to December 2005). A significant reduced form effect would suggest that mothers who have a peer who gave birth between January and June 2006 differ from those who give birth in the second half of 2005 . However, we find no first stage, reduced form or peer effects using the placebo sample.

Table 4: Results from placebo sample

\begin{tabular}{lccccr}
\hline & First stage & Reduced form & Peer effect & $\mathrm{N}$ & Controls \\
\hline \hline Placebo sample using & -0.022 & -0.017 & 0.805 & 1180 & No \\
a fake reform date & $(0.062)$ & $(0.027)$ & $(2.611)$ & & \\
& 0.000 & -0.017 & 42.847 & 1179 & Yes \\
& $(0.055)$ & $(0.026)$ & $(5974.627)$ & & \\
\hline & $* * * \mathrm{p}<0.01,{ }^{* *} \mathrm{p}<0.05, * \mathrm{p}<0.1$ & & \\
\hline
\end{tabular}

Note: The dependent variable $y_{C}$ is defined as an indicator equal to one if the individual does not return to work within 10 months following childbirth. First stage and reduced form regressions include the same control variables as the corresponding 2SLS regression. Standard errors (in parentheses) are clustered on firm level. Control variables include month of childbirth, age of the mother, prior-to-birth earnings and education level of both coworkers and peer mothers. Firm size, number of peer births in reform window, peer group size and a dummy for West Germany.

\section{Mechanisms}

Peer effects can operate through several channels of social interaction. One mechanism through which peer effects could arise is the transmission of information about the parental leave benefit program. Mothers may learn from their peers about the existence of the parental leave benefit program, its eligibility criteria, and the application procedure. However, we argue that this is not likely to be a relevant mechanism of peer effects in our context, because the program is well known and parents are generally informed about the organizational details of parental leave benefits. There is an easy-to-use online tool to compute expected benefits and the application form has to be filled in regardless of the length of the parental leave. An almost 100 percent take-up rate of at least some parental leave indicates that there is no lack of practical information in this context. Despite the general knowledge about parental leave benefits, observing peers at work could reveal information on career related consequences as well as the workplace-specific costs and benefits of parental leave. Women may, for example, acquire information from their female peers that reduces uncertainty about post-birth career opportunities, wage-trajectories, 
and the possibility of combining family and work. In a standard social learning model, we would expect that women with more diffuse priors about the costs and benefits of parental leave should be more strongly influenced by their peers (see Goyal, 2011, for an overview of models of social learning in networks). Consequently, we expect stronger peer effects in situations with greater career-related uncertainty, if the revelation of information is a driving mechanism of peer effects in our context. For example, we expect stronger peer effects for young mothers, women who have their first child, and for short tenure. Furthermore, we expect stronger peer effects in younger firms, firms with high turnover and firms with high job uncertainty, where workplace specific information is more valuable.

Table 5: Heterogenous effects - results for different subgroups

\begin{tabular}{rcccc}
\hline & First stage & Reduced form & Peer effect & $\mathrm{N}$ \\
\hline \hline Baseline & $0.215^{* * *}$ & $0.068^{* * *}$ & $0.315^{* * *}$ & 1340 \\
& $(0.060)$ & $(0.024)$ & $(0.116)$ & \\
\hline Long tenure in firm (days $\geq 720)$ & $0.191^{* * *}$ & 0.010 & 0.050 & 967 \\
& $(0.059)$ & $(0.029)$ & $(0.147)$ & \\
Short tenure in firm (days $<720)$ & $0.265^{* * *}$ & $0.193^{* * *}$ & $0.726^{* * *}$ & 369 \\
& $(0.084)$ & $(0.049)$ & $(0.265)$ & \\
Including only first births & $0.166^{* * *}$ & $0.060^{* *}$ & $0.364^{*}$ & 1028 \\
& $(0.059)$ & $(0.028)$ & $(0.199)$ & \\
Old firm (years $>10)$ & $0.180^{* * *}$ & $0.045^{*}$ & 0.253 & 1185 \\
& $(0.057)$ & $(0.026)$ & $(0.161)$ & \\
Young firm (years $\leq 10)$ & 0.357 & $0.229^{* * *}$ & 0.641 & 151 \\
& $(0.228)$ & $(0.072)$ & $(0.460)$ & \\
East Germany & $0.169^{*}$ & 0.019 & 0.110 & 463 \\
& $(0.099)$ & $(0.043)$ & $(0.258)$ & \\
West Germany & $0.201^{* * *}$ & $0.074^{* *}$ & $0.369^{* *}$ & 873 \\
& $(0.066)$ & $(0.030)$ & $(0.167)$ & \\
Small groups only (group size $\leq 50)$ & 0.100 & 0.034 & 0.341 & 791 \\
& $(0.062)$ & $(0.030)$ & $(0.374)$ & \\
\hline$* * * \mathrm{p}<0.01, * * \mathrm{p}<0.05, *$ & $\mathrm{p}<0.1$ & & \\
\hline
\end{tabular}

Note: The dependent variable $y_{C}$ is defined as an indicator equal to one if the individual does not return to work within 10 months after childbirth. First stage and reduced form regressions include the same control variables as the corresponding 2SLS regression. Standard errors (in parentheses) are clustered on firm level. Control variables include month of childbirth, age of the mother, prior-to-birth earnings and education level of both coworkers and peer mothers. Firm size, number of peer births in reform window, peer group size and a dummy for West Germany.

In order to test this hypothesis, we split the sample in two: those coworkers with short tenure (less than 720 days work experience at the present firm) and those with long tenure (more than 720 days at the same firm). Ceteris paribus, mothers with short tenure should face more uncertainty concerning the firm's reaction to their leave decision than mothers with long tenure. Thus, we expect larger peer effects for the former group. As Table 5 shows, we find a larger peer effect for mothers with short tenure. The LATE for this group is 0.73 , and 
the reduced form effect amounts to 0.19 percentage points. In contrast, for mothers with long tenure, the point estimate falls to 0.05 and is statistically insignificant. This evidence suggests that peer effect are at least partly driven by the reduction of uncertainty for mothers who wish to take longer leaves (longer than 10 months), because they can observe peers who took longer leaves in response to the parental leave benefit reform, as well as their employers reactions to it. In line with this argument, we find larger, although insignificant, peer effects if we restrict the sample to firms that are no more than 10 years old. Similarly, we expect mothers to face a higher uncertainty regarding the consequences of an extended parental leave if they gave birth to their first child, compared higher order births. Most birth events observed in our sample are first births, therefore we cannot compare the different effects by number of children. An analysis including only first births yields a slightly higher point estimate of the peer effect. Further sample divisions, e.g. by share of female employees, age, or education, are impeded by the small number of observations per group.

Competing explanations to the transmission of career-related information include imitation and herding behavior (Akerlof and Kranton, 2000; Banerjee, 1992). We summarize these explanations as preferences for conformity to norms within social reference groups. This can include peer pressure. Social norms regarding parental leave may differ by socio-economic status, employer, occupational group and region. For example, norms regarding parental leave differ greatly between East and West Germany. Even though the overall duration of parental leave before the reform was longer on average in the West, it was also more common to return within the first 10 months in West Germany compared to East Germany, where a one-year leave was a long standing tradition. The parental leave benefit reform changed societal norms toward a parental leave duration of one year. Consequently, this amounts to a larger change in social norms in West Germany than in the former East. Separate estimations for East and West Germany show that all three effects (first stage, reduced form and LATE) are larger in West than East Germany. Reduced form and peer effect estimates for East German mothers are not statistically significant. This could also be due to the relatively small number of observations in the sample of East German mothers. However, smaller effects in East Germany are consistent with a larger change in social norms in West Germany. A large fraction of East German mothers stayed at home for at least 10 months before the reform. As a result, the reform effect on our outcome variable is not as strong in the East as it is in the West.

Where the parental leave benefit reform did not change social norms substantially (e.g. in East Germany), peer effects are expected to be smaller. Note that we distinguish between information transmission in settings with career-related uncertainty and settings where social norms are in flux. We are, however, unable to clearly distinguish these two channels of peer effects empirically. Based on stronger peer effects for mothers with short tenure and East German mothers, we conclude information transmission about the costs and benefits of a long parental leave, as well as preferences for conformity to changing social norms may constitute important channels in settings where the reform had large direct effects. Our results are consistent with a social learning model where the information provided by peers reduces social and career-related 
uncertainty.

Previous literature suggests that leisure complementarities are another potential source of peer effects in labor supply decisions (see Alesina et al., 2006). A peer mother who is enjoying a long parental leave may induce her coworker to do the same, so that time can be spent together. On the other hand, the opposite could be true and the absence of one mother may reduce the probability that her coworkers will simultaneously take a long leave. In particular, in small firms, the absence of an employee can increase the workload and responsibilities of her coworkers and thereby make a (long) parental leave more costly. However, in our context, peer mothers and their coworkers give birth with a temporal distance and hence do not, generally speaking, take leave at the same time. Consequently, the scope for complementarities is limited because leave spells of peers and their coworkers often do not overlap. As a test of leisure complementarities, we restrict the sample to mothers whose peers gave birth at least nine months earlier. We find the similar effects (displayed in Table 2) and, hence, conclude that this is unlikely to be an important channel of peer effects in our context.

Furthermore, we expect larger effects as the peer groups get smaller, because our definition is only an approximation and many of the women who we define as peers may not actually interact with each other. Due to the small sample size, we are not able to estimate peer effects by different group and firm sizes. An analysis of small groups with 50 women or fewer in the same occupation and firm results in large but insignificant point estimates. However, the first stage estimate is insignificant for this sample and we can, therefore, only presume that peer effects are stronger in smaller groups and firms.

\section{Conclusion}

The decision of mothers regarding how long to take parental leave in order to take care of her children is influenced not only by financial considerations but also by peer behavior. In this paper, we estimate the quantitative importance of peers' decisions on the parental leave decisions of mothers, in particular on the probability to return to work within the first 10 months after giving birth.

We use exogenous variation in the length of parental leaves of mothers induced by a parental leave benefit reform in Germany in 2007 to identify "causal" peer effects. The reform strongly increased financial incentives to take a leave of one year, especially for medium- and high-income mothers. Using linked employer-employee data, this methodology allows us to identify the peer effect as the local average treatment effect for the group of mothers with coworkers who decided for a longer leave due to the reform. For this group, we find a statistically significant and large peer effect: if a mother has a peer who opted for a longer leave due to the reform, the probability that she will take parental leave for at least 10 months is about 30 percentage points higher than if her peer returned to work after no more than 10 months. This strong effect shows that the influence of peers is quantitatively important. The results are robust to a large set 
of different specifications with respect to the definition of the peer group, the definition of the estimation sample, as well as the inclusion of covariates.

Our results suggest that preferences for conformity and the transmission of information about the costs and benefits of a (long) parental leave are both relevant mechanism of peer effects in our context. Information transmission is expected to be particularly important in situations with high career-related uncertainty. We show that for the subgroup of women with short tenure at the same firm, a group that supposedly faces more uncertainty regarding the employer's reaction to leave decisions, the peer effect is much stronger than for the group with longer tenure. Preferences for conformity to peer behavior are expected to be particularly important in situations with changing social norms. In East Germany, where the parental leave benefit reform did not change social norms substantially, peer effects are expected to be smaller. Separate estimations for East and West Germany show that both direct reform effects and peer effects are larger in West than in East Germany. Our results are consistent with a social learning model where information provided by peers reduces social and career-related uncertainty.

Our results are also interesting from a policy point of view. We show that just the fact that a mother (who gave birth to a child after the reform has been implemented) has a peer who gave birth shortly after the introduction of the new parental leave scheme increases her probability of taking a longer leave by 7 percentage points in contrast to mothers with peers who gave birth to a child shortly before the reform. This effect, which can be interpreted as intention to treat effect, shows that policy reforms have an impact on the individuals' choices that go far beyond the immediate behavioral reaction due to changes in financial incentives. 


\section{References}

Akerlof, G. A. And R. E. Kranton (2000): "Economics and identity," Quarterly journal of Economics, 715-753.

Alesina, A. F., E. L. Glaeser, and B. Sacerdote (2006): "Work and Leisure in the US and Europe: Why so Different?" in NBER Macroeconomics Annual 2005, Volume 20, MIT Press, 1-100.

Angrist, J. D. And J.-S. Pischke (2009): Mostly Harmless Econometrics: An Empiricist's Companion, Princeton University Press.

BAnerJee, A. V. (1992): "A simple model of herd behavior," The Quarterly Journal of Economics, 797-817.

Beblo, M., C. Lauer, and K. Wrohlich (2005): "Ganztagsschulen und Erwerbsbeteiligung von Müttern: eine Mikrosimulationsstudie für Deutschland," ZEW Discussion Papers 05-93, Centre for European Economic Research, Mannheim.

Bergemann, A. And R. T. Riphahn (2011): "The introduction of a short-term earningsrelated parental leave benefit system and differential effects on employment intentions," Schmollers Jahrbuch: Journal of Applied Social Science Studies/Zeitschrift für Wirtschaftsund Sozialwissenschaften, 131, 315-325.

(2015): "Maternal Employment Effects of Paid Parental Leave," IZA Discussion Paper 9073, IZA - Institute for the Study of Labor, Bonn.

Bick, A. And N. Fuchs-Schündeln (2014): "Taxation and Labor Supply of Married Couples across Countries: A Macroeconomic Analysis," Unpublished working paper.

Blau, F. And L. Kahn (2006): "Changes in the Labor Supply Behavior of Married Women: 1980-2000," Journal of Labor Economics, 25, 393-438.

Blume, L. E., W. A. Brock, S. N. Durlauf, and Y. M. Ioannides (2010): "Identification of Social Interactions," in Handbook of Social Economics, ed. by J. Benhabib, A. Bisin, and M. O. Jackson, Elsevier, vol. 1.

Blume, L. E., W. A. Brock, S. N. Durlauf, and R. Jayaraman (2013): "Linear social interactions models," NBER discussion paper, National Bureau of Economic Research.

Blundell, R., A. Bozio, and G. Laroque (2013): "Extensive and Intensive Margins of Labor Supply," Fiscal Studies, 34, 1-29.

Bramoullé, Y., H. Djebbari, and B. Fortin (2009): "Identification of Peer Effects Through Social Networks," Journal of Econometrics, 150, 41-55.

Brock, W. A. And S. N. Durlauf (2001): "Discrete Choice with Social Interactions," The Review of Economic Studies, 68, 235-260. 
Brown, K. (2013): "The link between pensions and retirement timing: Lessons from California teachers," Journal of Public Economics, 98, 1-14.

Bundesanstalt FÜr Arbeit, NÜRnBerg (1988): Klassifizierung der Berufe: systematisches und alphabetisches Verzeichnis der Berufsbenennungen.

Bundesministerium für Familien, Senioren, Frauen und Jugend (2012): "Dossier Müttererwerbstätigkeit: Erwerbstätigkeit, Erwerbsumfang und Erwerbsvolumen,” .

Cornelissen, T., C. Dustmann, and U. Schönberg (2013): "Peer Effects in the Workplace," IZA Discussion Paper 7617, IZA - Institute for the Study of Labor, Bonn.

Dahl, G. B., K. V. Løken, and M. Mogstad (2014): "Peer Effects in Program Participation," American Economic Review, 104, 2049-74.

Dearing, H., H. Hofer, C. Lietz, R. Winter-Ebmer, and K. Wrohlich (2007): "Why are mothers working longer hours in Austria than in Germany? Evidence from a comparative microsimulation study," Fiscal Studies, 28, 463-495.

Del Boca, D., M. Locatelli, And S. Pasqua (2000): "Employment Decisions of Married Women: Evidence and Explanations," Labour, 14, 35-52.

Dustmann, C., A. Glitz, And U. Schönberg (2011): "Referral-based job search networks," IZA Discussion Paper 5777, IZA - Institute for the Study of Labor, Bonn.

Dustmann, C. And U. Schönberg (2011): "Expansions in Maternity Leave Coverage and Children's Long-Term Outcomes," American Economic Journal: Applied Economics, 4, 190224.

Fernandez, R. (2013): "Cultural Change as Learning: The Evolution of Female Labor Force Participation over a Century," American Economic Review, 103, 472-500.

Fitzenberger, B. And G. Wunderlich (2004): "The Changing Life-Cycle Pattern in Female Employment: A Comparison of Germany and the UK," Scottish Journal of Political Economy, $51,302-328$.

Fogli, A. And L. Veldkamp (2011): "Nature or Nurture? Learning and the Geography of Female Labor Force Participation," Econometrica, 79, 1103-1138.

Geyer, J., P. HaAn, and K. Wrohlich (2015): "The effects of family policy on mothers' labor supply: Combining evidence from a structural model and a quasi-experimental approach," Labour Economics, 36, 84-98.

Glaeser, E. L., J. A. Scheinkman, And B. I. Sacerdote (2003): "The Social Multiplier," Journal of the European Economic Association, 1, 345-353.

Goldin, C. (1990): Understanding the Gender Gap: An Economic History of American Women, New York: Oxford University Press. 
Goyal, S. (2011): "Chapter 15: Learning in Networks," in Handbook of Social Economics, Elsevier, vol. 1.

Grunow, D. AND D. Müller (2012): "Kulturelle und strukturelle Faktoren bei der Rückkehr in den Beruf: ostdeutsche, westdeutsche und ost-west-mobile Mütter im Vergleich," Zeitschrift für Familienforschung. Sonderheft, 55-77.

Hesselius, P. (2009): "Sick of your colleagues' absence?" Journal of the European Economics, $7,583-594$.

INKAR (2015): "Indikatoren und Karten zur Raum- und Stadtentwicklung," Bundesinstitut für Bau-, Stadt- und Raumforschung (BBSR) im Bundesamt für Bauwesen und Raumordnung (BBR), Bonn.

John, B. AND E. STUtzer (2002): "Erwerbsverhalten von Erziehungsurlauberinnen," Zeitschrift für Familienforschung, 14, 215-233.

Kluve, J. And S. Schmitz (2014): "Social Norms and Mothers' Labor Market Attachment. The Medium-run effects of parental benefits," Discussion Paper 481, Ruhr Economic Papers.

Kluve, J. And M. TAmm (2013): "Parental leave regulations, mothers' labor force attachment and fathers' childcare involvement: evidence from a natural experiment," Journal of Population Economics, 26, 983-1005.

Manski, C. F. (1993): "Identification of endogenous social effects: The reflection problem," The review of economic studies, 60, 531-542.

Marcus, J., J. Nemitz, And C. K. Spiess (2013): "Ausbau der Ganztagsschule: Kinder aus einkommensschwachen Haushalten im Westen nutzen Angebote verstärkt," $D I W$ Wochenbericht, 80, 11-23.

Mas, A. and E. Moretti (2009): "Peers at work," American Economic Review, 99, 112-145.

MAURIn, E. AND J. Moschion (2009): "The social multiplier and labor market participation of mothers," American Economic Journal: Applied Economics, 1, 251-272.

Neumark, D. And A. Postlewaite (1998): "Relative income concerns and the rise in married women's employment," Journal of Public Economics, 70, 157-183.

Nicoletti, C., K. G. Salvanes, And E. Tominey (2016): "The Family Peer Effect on Mothers' Labour Supply," IZA Discussion Paper 9927, IZA - Institute for the Study of Labor, Bonn.

Pink, S., T. Leopold, And H. Engelhardt (2013): "Fertility and social interaction at the workplace: Does childbearing spread among colleagues?" Advances in Life Course Research.

PolacheK, S. And J. Xiang (2006): "The gender pay gap: a cross-country analysis," Unpublished paper, SUNY-Binghamton. 
RAute, A. (2014): "Do financial incentives affect fertility-Evidence from a reform in maternity leave benefits," Job market paper.

Rosenfeld, R. A., H. Trappe, and J. C. Gornick (2004): "Gender and work in Germany: Before and after reunification," Annual Review of Sociology, 103-124.

Ruhm, C. J. (1998): "The Economic Consequences of Parental Leave Mandates: Lessons from Europe," The Quarterly Journal of Economics, 113, 285-317.

SchÖNBERG, U. (2009): "Does the IAB employment sample reliably identify maternity leave taking? A data report," Zeitschrift für Arbeitsmarkt Forschung, 42, 49-70.

Schönberg, U. And J. Ludsteck (2014): "Expansions in Maternity Leave Coverage and Mothers' Labor Market Outcomes after Childbirth," Journal of Labor Economics, 32, 469505.

Spiess, C. K. (2011): "Vereinbarkeit von Familie und Beruf-wie wirksam sind deutsche Care Policies?" Perspektiven der Wirtschaftspolitik, 12, 4-27.

TAmm, M. (2013): "The Impact of a Large Parental Leave Benefit Reform on the Timing of Birth around the Day of Implementation," Oxford Bulletin of Economics and Statistics, 75, $585-601$.

Weber, A. M. (2004): "Wann kehren junge Mütter auf den Arbeitsmarkt zurück? Eine Verweildaueranalyse für Deutschland," ZEW Discussion Paper 04-08, Centre for European Economic Research, Mannheim.

Weinberg, B. A., P. B. Reagan, and J. J. Yankow (2004): "Do Neighborhoods Affect Hours Worked ? Evidence from Longitudinal Data," Journal of Labor Economics, 22, 891924.

Wrohlich, K., E. Berger, J. Geyer, P. Haan, D. Sengül, C. K. Spiess, and A. ThieMANN (2012): "Elterngeld Monitor. Forschungsprojekt im Auftrag des Bundesministeriums für Familie, Senioren, Frauen und Jugend," Politikberatung kompakt. 


\section{Appendix}

Figure 7: Fraction of mothers who stays at home for at least 10 months after childbirth by income group and region

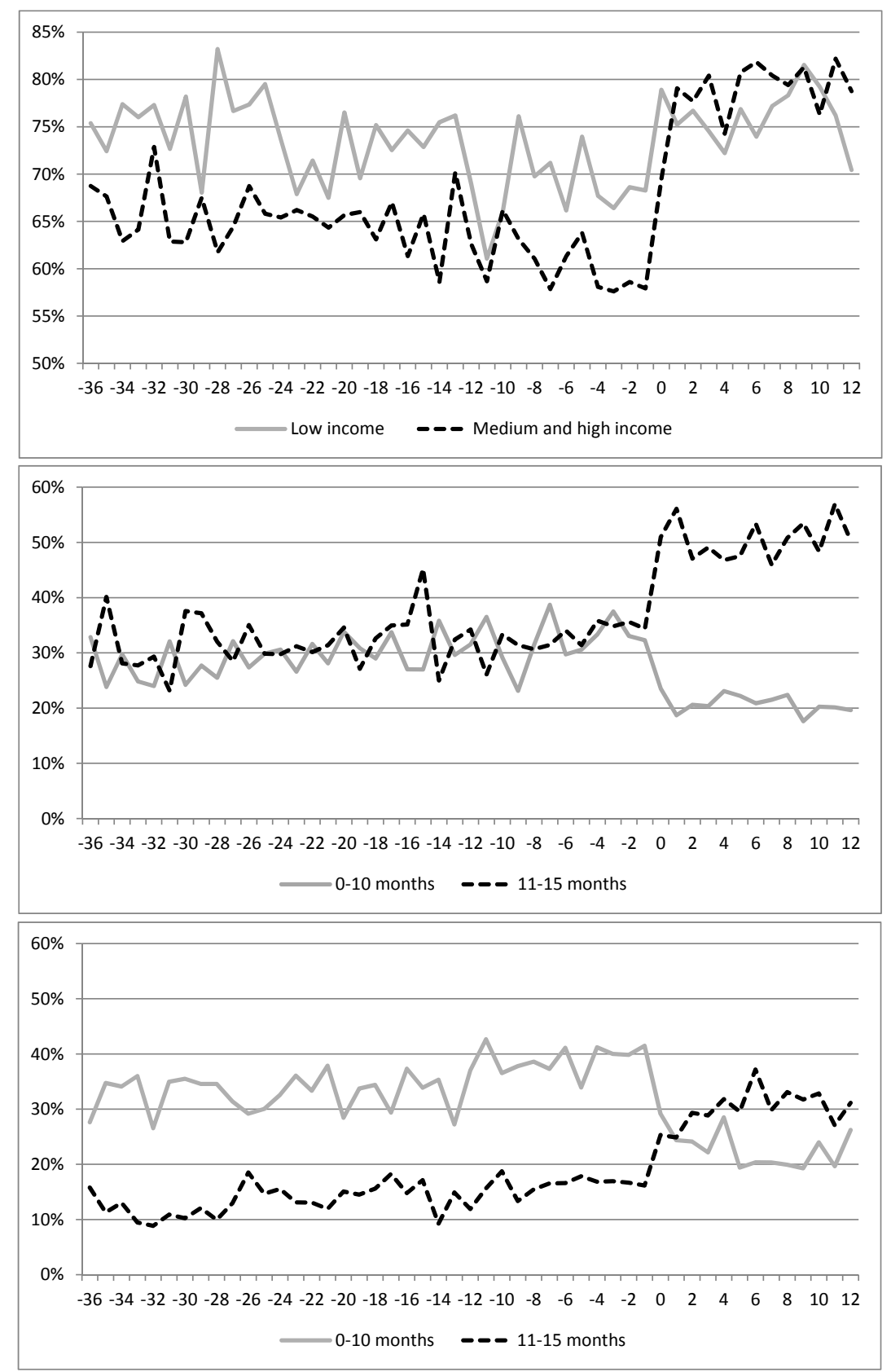

The figure is based on our own analysis using the LIAB. Fractions are calculated out of all women in the sample who gave birth in a given month, in distance to the parental leave benefit reform (January 2007 $=0)$. Low income refers to the bottom third of the gross labor income distribution. 


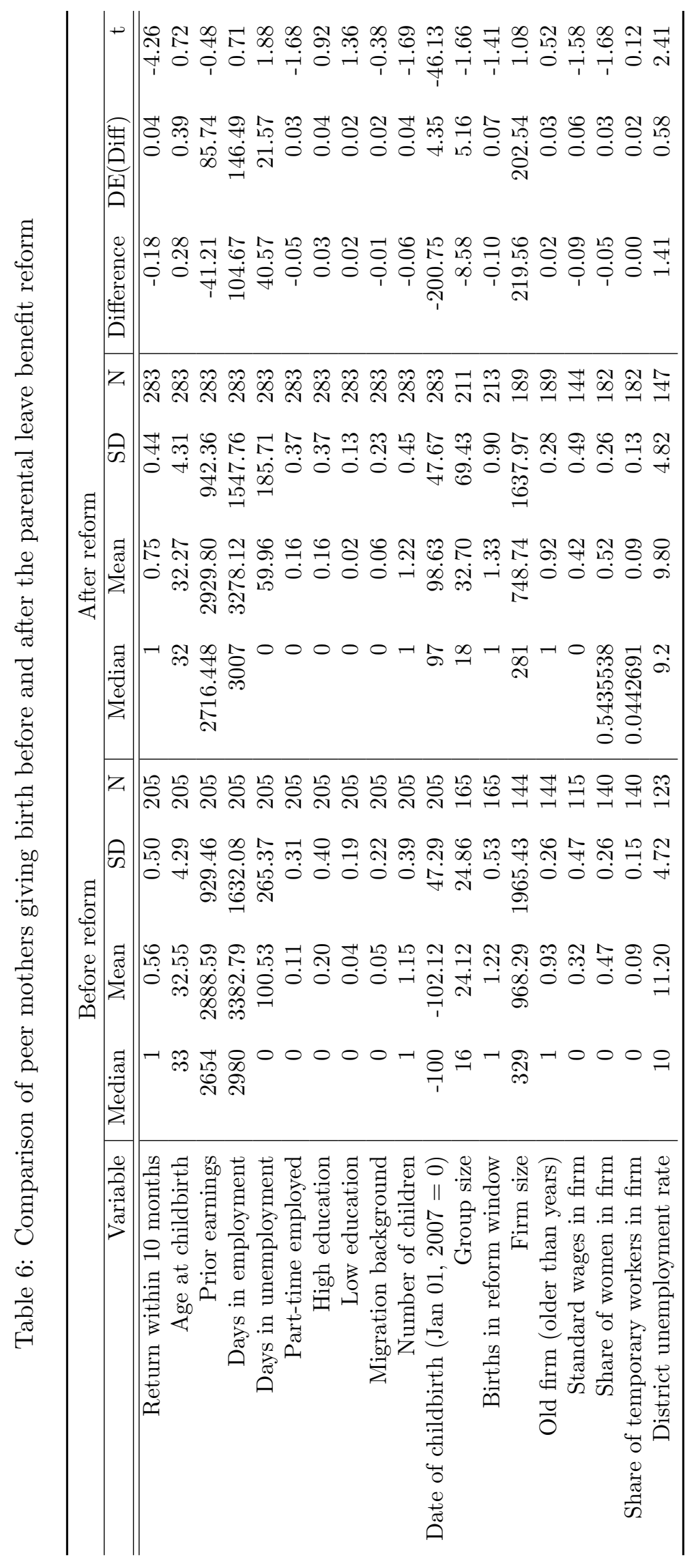




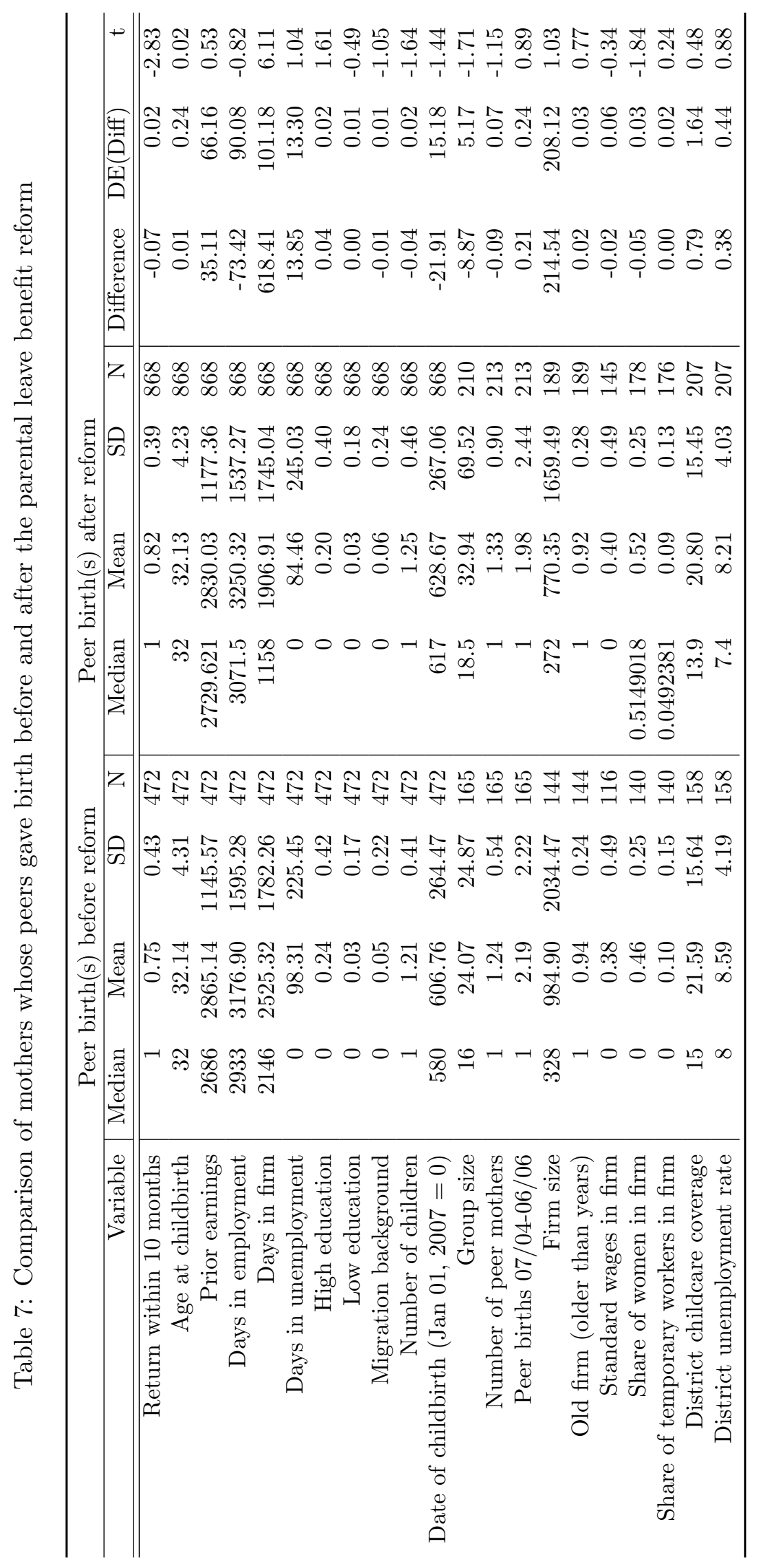


Figure 8: Distribution of births per month in distance to January of each year

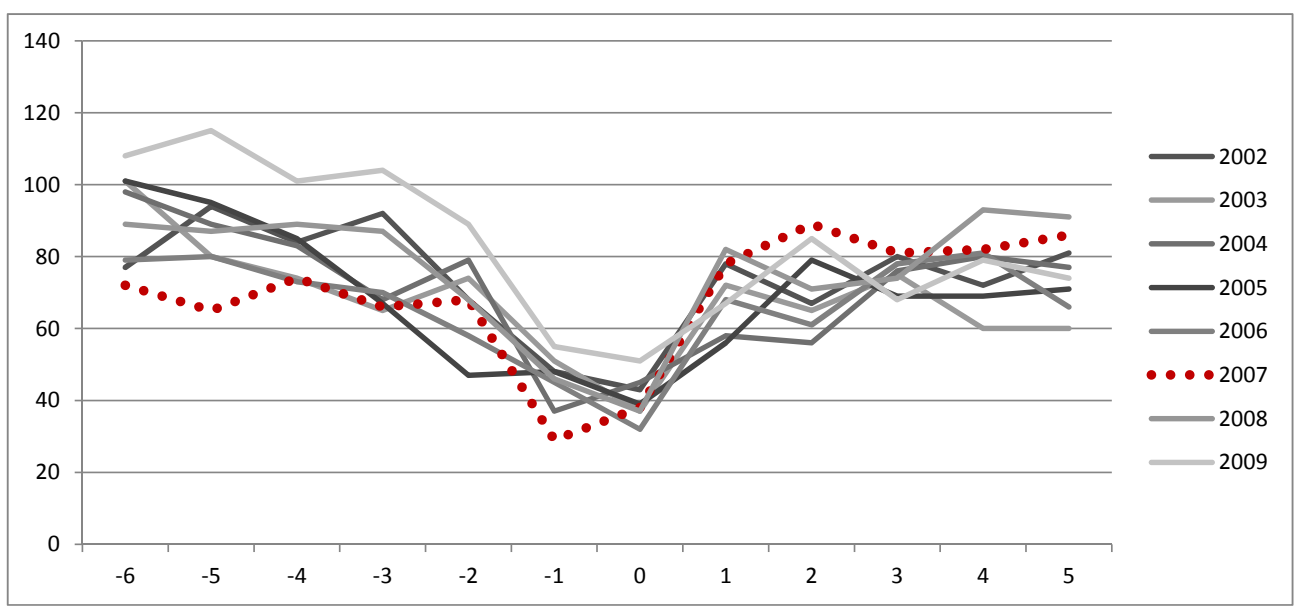

Calculations are based on the baseline sample specification sample with either births before or after January 1st in a one-year window around the (hypothetical) reform-date.

Table 8: Sample sizes relative to total number of births $(07 / 2007-12 / 2009)$

\begin{tabular}{lrrrrrr}
\hline & Baseline & Sample C & Sample D & Sample E & Sample F & Sample G \\
\hline Coworkers & 1340 & 3202 & 1245 & 1089 & 1107 & 1482 \\
Percent of births & $11.1 \%$ & $25.5 \%$ & $10.3 \%$ & $9.0 \%$ & $9.2 \%$ & $12.3 \%$ \\
\hline Peer mothers & 488 & 1375 & 450 & 334 & 467 & 345 \\
\hline Baseline specification: either births before or after the cutoff date in the reform window \\
Sample A: Using all observations where there is at least one birth in the reform window. \\
Sample B: Limit reform window to births that occur at least 30 days before/after cutoff. \\
Sample C: Peer groups are defined to be equal to firms. \\
Sample D: Restrict coworker birth to be at least 9 months after last peer birth. \\
Sample E: Limit reform window to 6 months (3 before and 3 after reform). \\
\hline
\end{tabular}


Table 9: Baseline sample characteristics in comparison to all observed mothers

\begin{tabular}{|c|c|c|c|c|c|c|}
\hline & \multicolumn{3}{|c|}{ All mothers } & \multicolumn{3}{|c|}{ Sample } \\
\hline & Mean & $\mathrm{SD}$ & $\mathrm{N}$ & Mean & $\mathrm{SD}$ & $\mathrm{N}$ \\
\hline Return within 10 months & 0.79 & 0.41 & 12069 & 0.79 & 0.41 & 1340 \\
\hline Return within 11-15 months & 0.40 & 0.49 & 11111 & 0.42 & 0.49 & 1222 \\
\hline Return within 24 months & 0.25 & 0.44 & 7682 & 0.24 & 0.43 & 848 \\
\hline Age at childbirth & 31.79 & 4.52 & 12069 & 32.14 & 4.25 & 1340 \\
\hline Prior earnings & 2365.38 & 1159.50 & 12069 & 2842.40 & 1165.95 & 1340 \\
\hline Days in employment & 3196.19 & 1562.36 & 12069 & 3224.46 & 1557.75 & 1340 \\
\hline Days in firm & 2448.60 & 1770.78 & 12069 & 2124.74 & 1782.24 & 1340 \\
\hline Days in unemployment & 128.17 & 339.66 & 12069 & 89.34 & 238.32 & 1340 \\
\hline Part-time employed & 0.31 & 0.46 & 12069 & 0.25 & 0.43 & 1340 \\
\hline High education & 0.13 & 0.33 & 12069 & 0.21 & 0.41 & 1340 \\
\hline Low education & 0.04 & 0.20 & 12069 & 0.03 & 0.18 & 1340 \\
\hline Migration background & 0.05 & 0.22 & 12069 & 0.06 & 0.23 & 1340 \\
\hline Number of children & 1.32 & 0.52 & 12069 & 1.24 & 0.44 & 1340 \\
\hline Date of childbirth (Jan 01, 2007 is zero) & 621.75 & 258.20 & 12069 & 620.95 & 266.26 & 1340 \\
\hline West Germany & 0.59 & 0.49 & 12069 & 0.65 & 0.48 & 1340 \\
\hline Employer change upon return & 0.18 & 0.38 & 9197 & 0.18 & 0.38 & 1028 \\
\hline Group size & 31.29 & 110.59 & 3031 & 28.99 & 54.70 & 375 \\
\hline Births in group & 1.09 & 4.75 & 3321 & 1.20 & 0.83 & 378 \\
\hline Firm size & 268.90 & 722.53 & 1927 & 722.72 & 1482.01 & 311 \\
\hline Old firm ( $\geq 10$ years $)$ & 0.80 & 0.40 & 1933 & 0.93 & 0.26 & 311 \\
\hline Standard wages & 0.33 & 0.47 & 1146 & 0.37 & 0.48 & 243 \\
\hline Median gross daily income in firm & 83.51 & 30.88 & 1884 & 104.09 & 26.12 & 311 \\
\hline Share of part-time workers in firm & 0.25 & 0.26 & 1812 & 0.21 & 0.20 & 294 \\
\hline Share of women in firm & 0.53 & 0.28 & 1825 & 0.51 & 0.25 & 297 \\
\hline Share of temporary workers in firm & 0.09 & 0.16 & 1815 & 0.09 & 0.14 & 295 \\
\hline District childcare coverage & 17.91 & 13.40 & 380 & 20.26 & 14.85 & 252 \\
\hline District population density & 530.71 & 689.02 & 380 & 556.53 & 731.64 & 252 \\
\hline District unemployment rate & 7.74 & 3.80 & 380 & 8.13 & 4.09 & 252 \\
\hline
\end{tabular}

$\overline{A l l}$ mothers refers to all women in the LIAB who gave birth between July 2007 and December 2009. 


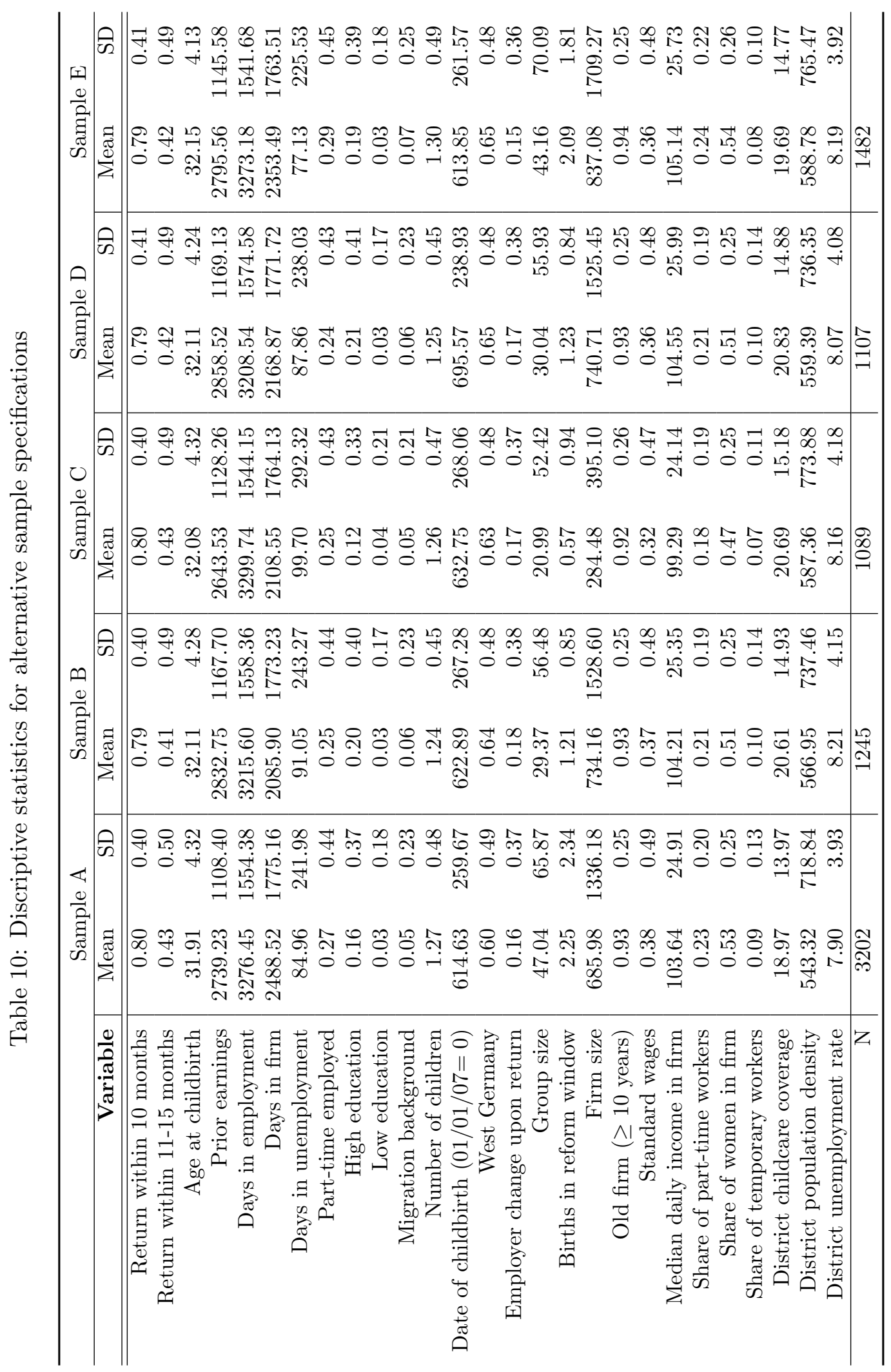




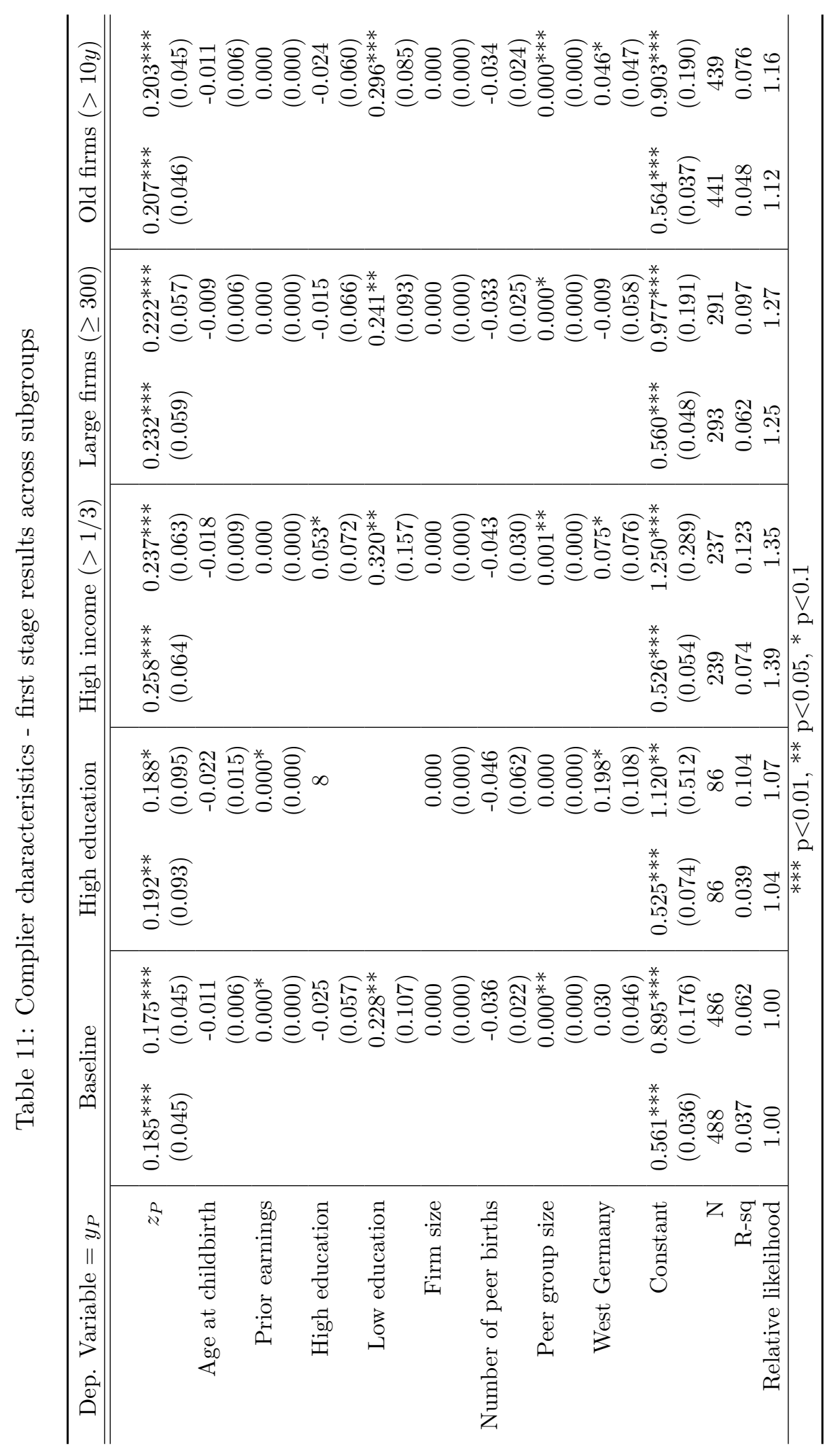

